\title{
¿Changes in Soil Moisture Persistence in China over the Past 40 Years under a Warming Climate $\mathscr{A}$
}

\author{
MingXing Li, ${ }^{\mathrm{a}}$ Peili Wu, ${ }^{\mathrm{b}}$ Zhuguo Ma, ${ }^{\mathrm{a}, \mathrm{c}}$ Meixia Lv, ${ }^{\mathrm{a}}$ And Qing Yang ${ }^{\mathrm{a}}$ \\ ${ }^{a}$ Key Laboratory of Regional Climate-Environment for Temperate East Asia, Institute of Atmospheric Physics, Chinese Academy of \\ Sciences, Beijing, China $;{ }^{\mathrm{b}}$ Met Office Hadley Centre, Exeter, United Kingdom; ${ }^{\mathrm{c}}$ University of Chinese Academy of Sciences, \\ Beijing, China
}

(Manuscript received 6 December 2019, in final form 16 August 2020)

\begin{abstract}
Variability in soil moisture has implications for regional terrestrial environments under a warming climate. This paper focuses on the spatiotemporal variability in the intra-annual persistence of soil moisture in China using the fifthgeneration reanalysis dataset by the European Centre for Medium-Range Weather Forecasts for the period 1979-2018. The results show that in China, the mean intra-annual persistence in the humid to arid zones increased from 60 to 115 days in the lower layer but decreased from 19 to 13 days and from 25 to 14 days in the upper and root layers, respectively. However, these changes were strongly attenuated in extremely dry and wet regions due to the scarcity of soil moisture anomalies. Large changes in persistence occurred in the lower soil layer in dryland areas, with a mean difference of up to 40 days between the 2010s and the 1980s. Overall increasing trends dominated the large-scale spatial features, despite regional decreases in the eastern arid zone and the North and Northeast China plains. In the root layer, the two plains experienced an expanded decrease while on the Tibetan Plateau it was dominated by decadal variability. These contrasting changes between the lower and root layers along the periphery of the transition zone was a reflection of the enhanced soil hydrological cycle in the root layer. The enhanced persistence in drylands lower layer is an indication of the intensified impacts of soil moisture anomalies (e.g., droughts) on terrestrial water cycle. These findings may help the understanding of climate change impacts on terrestrial environments.
\end{abstract}

KEYWORDS: Data assimilation; Hydrologic models; Land surface model; Climate variability; Decadal variability; Ecosystem effects

\section{Introduction}

Soil moisture plays a unique role in Earth's climate system because of its involvement in the water cycle, energy partitioning, and biogeochemical processes (Cowan 1965; Seneviratne et al. 2010; Green et al. 2019). During land-atmosphere interactions, some atmospheric anomalies can propagate and persist in the soil longer than in the atmosphere, leading to the persistence of soil moisture anomalies (also termed soil moisture memory) (Delworth and Manabe 1989; Koster and Suarez 2001). The persistence of soil moisture reflects a combination of the regional climate and its interactions with the local soil, vegetation, and topography (Orth and Seneviratne 2012). For this reason, variability in soil moisture persistence occurs in response to climate change and reflects its impacts on terrestrial processes. Studies of soil moisture persistence help further the awareness of the impacts of climate change on terrestrial environments.

In the land-atmosphere system, soil moisture persistence has long been recognized as a contributing factor when predicting atmospheric variations on monthly and seasonal time

๑ Denotes content that is immediately available upon publication as open access.

Supplemental information related to this paper is available at the Journals Online website: https://doi.org/10.1175/JCLI-D-190900.s1.

Corresponding author: Mingxing Li, limx@tea.ac.cn scales (Yeh et al. 1984; Delworth and Manabe 1989; Koster et al. 2010). The lag autocorrelation property of the evolution of soil moisture over time can prolong the effects of atmospheric anomalies (from two weeks to several months) in landatmosphere interactions. This property mainly depends on two mechanisms: the interactions between soil moisture and precipitation and the intensity of variations in the two variables (Orth and Seneviratne 2012). The mechanisms suggest that soil moisture persistence stems from precipitation persistence; soil-precipitation interactions are, however, modulated by the natures of the soil, vegetation, topography, and local climate regimes. On the regional and global scales, findings based on both models and observations show that actual evaporation strongly regulates the persistence of seasonal soil moisture anomalies; soil moisture persistence is inversely proportional to actual evaporation. In dry areas, low actual evaporation contributes to long persistence (Liu and Avissar 1999; Koster and Suarez 2001; Mahanama and Koster 2005). This mechanism is also confirmed by in situ observations in China (Wang and Shi 2019). Furthermore, vegetation plays an important role in evapotranspiration: approximately $50 \%-80 \%$ of water is transported by the root uptake of deep subsurface water; thus, the biological processes of plants also affect the persistence of soil moisture (Coenders-Gerrits et al. 2014; Chang et al. 2018). Additionally, runoff, snowpack, and other hydrological processes are important in shaping soil moisture persistence (Liu and Avissar 1999; Orth and Seneviratne 2012). In summary, soil moisture persistence reflects the responses of land processes, as well as their feedbacks, to atmospheric anomalies; therefore, studies on soil moisture persistence changes are 
helpful in assessing the impacts of climate change on terrestrial environments.

To date, the effects of climate change on terrestrial environments, according to atmospheric indicators, e.g., the ratio of annual precipitation to potential evapotranspiration, show that dryland expansion will increase in the twenty-first century, especially in mid- to high latitudes (Feng and Fu 2013; Huang et al. 2016). The standardized precipitation-evapotranspiration index suggests that droughts have particularly strong impacts on ecosystems in the tropics and high northern latitudes (Schwalm et al. 2017). On the other hand, studies have revealed spatiotemporal discrepancies between ecosystem behaviors and atmospheric climate variability. For example, during the 2015-16 Amazon drought (one of the two most severe meteorological droughts since 1901), $21.6 \%$ of forests greened up (Yang et al. 2018). Greening trends-observed at high latitudes, in northern China, and the Sahel region-cannot be simply attributed to increases in precipitation (Dardel et al. 2014; Adler et al. 2017; Zhang et al. 2017). Furthermore, different approaches have revealed that the estimates of reduced gross primary production during the 2003 European drought are widely divergent (ranging from -0.02 to $-0.27 \mathrm{Pg}$ of carbon) (Vetter et al. 2008; Schewe et al. 2019). These findings indicate that the impacts of climate change on environments are usually neither direct nor immediate; thus, atmospheric-only indicators or methods are necessary but not sufficient to assess climate impacts on ecosystems and environments.

The soil acts as an interface between land-atmosphere interactions, and soil moisture is involved in the flow of water, heat, and carbon in the soil-plant-atmosphere continuum (Cowan 1965); thus, it transports and regulates the impact of atmospheric climate anomalies on terrestrial ecosystems and environments. For instance, the spatial variability in soil moisture largely contributes to the spatial heterogeneity of the soil-moisture-evapotranspiration-precipitation coupling in China ( $\mathrm{Li}$ and $\mathrm{Ma}$ 2015; Li et al. 2017). Furthermore, previous studies have shown the functional dependence of stomatal conductance on soil moisture availability at the scale of plant leaves, and soil moisture, along with temperature, can significantly capture regional vegetation dynamics (Emanuel et al. 2007; Djebou and Singh 2015). In this regard, the variability in soil moisture persistence indicates a profound change in the impact of climate change on local environments. However, owing to the limited observations and low fidelity of model soil moisture data, the variability in soil moisture persistence on a regional scale largely remains an open issue in China.

In response to the current knowledge gap in soil moisture, this study focuses on the spatiotemporal variability in soil moisture persistence from 1979 to 2018 in China. The goal is to assess the variability in soil moisture persistence in response to regional climate change and provide implications for assessing climate change impacts. To this end, we quantify soil moisture persistence using the latest reanalysis dataset (ERA5) from the European Centre for Medium-Range Weather Forecasts (ECMWF). The details of the data and methods used are described in section 2. The fidelity of the ERA5 soil moisture data is evaluated using in situ observations in section 3 , and the main results, including the variability and seasonality of soil moisture persistence, follow. The possible mechanisms of persistence's response to regional climate change, as well as implications for dryland expansion in China, are discussed in section 4. The paper is summarized with conclusions in section 5 .

\section{Data and methodology}

\section{a. Data}

\section{1) REANALySis SOIL MOISTURE DATA OF THE ERA5}

The reanalysis soil moisture data used herein are taken from the fifth generation of the global atmospheric reanalysis by ECMWF, the latest development after the widely used ERAInterim and ERA-40 data (Hersbach et al. 2018). ERA5 is produced using high-resolution forecasts from the ECMWF's Integrated Forecast System (IFS) with the land surface model Hydrology Tiled ECMWF Scheme for Surface Exchanges over Land (HTESSEL; Balsamo et al. 2015). The HTESSEL includes six land surface tiles (bare ground, low and high vegetation, intercepted water, and shaded and exposed snow), in which soil water transfers take freeze-thaw processes into account (Viterbo and Beljaars 1995; Viterbo et al. 1999). Furthermore, the representations of snow hydrological processes were improved: they now account for snow liquid water and include revised formulations for snow density, snow cover fraction, and snow albedo (Balsamo et al. 2011). In terms of soil hydrology, the HTESSEL incorporates a spatially varying soil type and improved soil hydraulic and surface runoff schemes based on local soil properties (Balsamo et al. 2011). Thus, the terrestrial hydrological dynamics in ERA5, along with the relevant seasonality of vegetation, are significantly improved over those in its predecessor (Hersbach et al. 2018). The soil moisture also benefits from improvements in the data assimilation methodology. Through an extended Kalman filter, ERA5 assimilates scatterometer soil moisture products to improve its temporal evolution. Uniquely, this inclusion brings ERA5's decadal-scale time series of soil moisture into alignment with satellite-based soil moisture products. A detailed overview of the innovation and performance of ERA5 can be found in Hersbach et al. (2018).

In this study, the soil moisture is presented with a horizontal resolution of a $0.25^{\circ}$ latitude-longitude grid and has four vertical layers corresponding to depths of 7,28, 100, and $289 \mathrm{~cm}$ below the ground surface; its hourly dataset (in UTC) is used for the years 1979-2018. The soil moisture includes liquid and solid phases (e.g., ice, when the soil is frozen) in the form of volumetric soil moisture.

\section{2) IN SITU OBSERVATIONS OF SOIL MOISTURE}

To evaluate the reanalysis soil moisture data in ERA5, in situ observational soil moisture data were obtained from the International Soil Moisture Network (ISMN, https://ismn.geo. tuwien.ac.at) (Dorigo et al. 2011) and China Meteorological Administration (CMA, http:/www.cma.gov.cn/2011qxfw/2011qsjcx), including 956 sites in six networks, spanning 1981-2016. Detailed information on sites, networks, and records is listed in 
TABLE 1. Information on soil moisture observations and observational networks in China.

\begin{tabular}{|c|c|c|c|c|c|c|c|}
\hline No. & Networks & $\begin{array}{l}\text { Site } \\
\text { size }\end{array}$ & Data periods & $\begin{array}{l}\text { Depths } \\
\text { (m) }\end{array}$ & $\begin{array}{c}\text { SM } \\
\text { units }\end{array}$ & $\begin{array}{c}\text { Data } \\
\text { intervals }\end{array}$ & References \\
\hline 1 & CMA & 40 & 1981-99 & $0-1,10$ layers & $\mathrm{m}^{3} \mathrm{~m}^{-3}$ & 10 days & Liu et al. (2001) \\
\hline 2 & CTP_SMTMN & 34 & $2010-16$ & $0.1,0.2,0.4$ & $\mathrm{~m}^{3} \mathrm{~m}^{-3}$ & Hourly & Yang et al. (2013) \\
\hline 3 & HiWATER_EHWSN & 51 & June-September 2012 & $0.1,0.2,0.4$ & $\mathrm{~m}^{3} \mathrm{~m}^{-3}$ & Hourly & Jin et al. (2014) \\
\hline 4 & MAQU & 20 & $2008-10$ & 0.05 & $\mathrm{~m}^{3} \mathrm{~m}^{-3}$ & Hourly & Su et al. (2011) \\
\hline 5 & SW-WHU & 3 & $\begin{array}{l}\text { November-December } \\
\text { 2014; January, May } 2015\end{array}$ & 0.1 & $\mathrm{~m}^{3} \mathrm{~m}^{-3}$ & Hourly & Chen et al. (2015) \\
\hline 6 & CMA_Agr & 808 & 1991-2013 & $0.1,0.2,0.5$ & Relative $\mathrm{SM}^{\mathrm{a}}$ & Monthly ${ }^{\mathrm{b}}$ & $\begin{array}{l}\text { http://www.cma.gov.cn/ } \\
\text { 2011qxfw/2011qsjcx }\end{array}$ \\
\hline
\end{tabular}

${ }^{\text {a }}$ Relative soil moisture is the percentage of soil moisture relative to field capacity.

${ }^{\mathrm{b}}$ Monthly mean is derived from in situ observations with a 10-day interval.

Table 1 with their geographical distributions shown in Fig. 1. These observations were obtained with two methods: the gravimetric method and the sensor method. The routine measurements in China with the gravimetric method were conducted on the 8 th, 18th, and 28th days of every month, excluding rainy days and frozen periods. To benefit agricultural practices, the records of the network CMA_Agr were released in the form of relative soil moisture with respect to field capacity. However, the network CMA uses volumetric soil moisture. The in situ sensor-measured soil moisture in the other four networks is also recorded in the form of volumetric soil moisture. Given that the observations of five networks, as well as the ERA5 reanalysis, are consistently in volumetric soil moisture, the relative soil moisture of the network CMA_Agr is converted into volumetric soil moisture based on the following relationships (Maidment 1993):

$$
\begin{aligned}
& \theta=w / \beta_{w} \times \beta_{d}, \\
& w=R \times \mathrm{FC},
\end{aligned}
$$

where $\theta$ and $w$ stand for volumetric and gravimetric soil moisture $\left(\mathrm{cm}^{3} \mathrm{~cm}^{-3}, \mathrm{~g} \mathrm{~g}^{-1}\right)$, respectively; $\beta_{w}$ and $\beta_{d}$ represent the bulk densities of water and soil $\left(\mathrm{g} \mathrm{cm}^{-3}\right)$, respectively, with $\beta_{w}$ assumed to be $1 \mathrm{~g} \mathrm{~cm}^{-3}$ normally; $R$ denotes the relative soil moisture; FC is the field capacity, i.e., the maximum soil moisture retained in soil under gravity. Herein, the FC data are taken from Dai et al. (2013) and were estimated with the empirical pedotransfer functions based on observed soil parameters (e.g., bulk density). For detailed descriptions of the estimation, refer to Dai et al. (2013) and the references cited therein. Additionally, the four non-CMA networks mainly serve specific scientific purposes, i.e., CTP_SMTMN was set up for monitoring soil moisture freeze-thaw changes, HiWATER EHWSN for ecohydrological monitoring, MAQU for quantifying uncertainties in coarse-resolution satellite and model products, and SW-WHU for testing an online control method for in situ sensors (Table 1). Although the sensors can work in seconds, mean hourly data are publicly available. Importantly, all in situ observations have been subjected to sensor calibration and rigorous data quality control, considering sensor properties, accidental interference, and outliers. For more details, refer to the network reports and the references therein (available from https://ismn.geo.tuwien.ac.at).
Owing to the scarcity of observations, all available sites with more than 30 records are used here to expand the spatial coverage. For this reason, the sample sizes vary among the sites (Table 1, Fig. 2). Nonetheless, they meet the requirements of the large sample theory, thereby ensuring the validity of subsequent statistical analysis. The observations in the $0-100-\mathrm{cm}$ soil layer (mean of 10 layers, Table 1) in the network CMA are compared with the ERA5 reanalysis data in the same layer [mean of the first three layers, section $2 \mathrm{a}(1)$ ]. For networks MAQU and SW-WHU, observations at 5- and 10-cm depths are directly compared with the reanalysis data in the $0-7-\mathrm{cm}$ layer. For the networks CTP_SMTMN, HiWATER_EHWSN, and CMA_Agr, the observations at 10-, 20-, and 40-/50-cm depths are used to interpolate the values for the 0-28-cm layer matching the first two layers of the ERA5 dataset, as in Li et al. (2005). In addition, the in situ measurement was temporarily suspended during frozen periods in the networks CMA and CMA-Agr, conducted from June to September in 2012 within the HiWATER_EHWSN, and the minimum soil temperature at three sites of the SW-WHU was higher than $0^{\circ} \mathrm{C}$. Thus, only at the sites within CTP_SMTMN and MAQU was the observed soil moisture affected by soil freeze-thaw processes.

\section{b. Methodology}

1) QuANTIFICATION OF SOIL MOISTURE PERSISTENCE

Soil moisture persistence is quantified using the lag autocorrelation of soil moisture anomalies over specific time frames, given that the autocorrelation in soil moisture represents the persistence of a combination of wet/dry soil moisture states forced by land-atmosphere interactions (Delworth and Manabe 1988; Koster and Suarez 2001; Orth and Seneviratne 2012). The lag autocorrelation in soil moisture is estimated by the Pearson correlation as Eq. (3) based on daily mean soil moisture according to Santanello et al. (2018):

$$
r_{t}=\frac{1}{T} \sum_{t=1}^{T}\left(x_{t}-\bar{x}\right)\left(y_{t}-\bar{y}\right) / \sqrt{\frac{1}{T} \sum_{t=1}^{T}\left(x_{t}-\bar{x}\right)^{2}} \sqrt{\frac{1}{T} \sum_{t=1}^{T}\left(y_{t}-\bar{y}\right)^{2}},
$$

where $x_{t}$ and $y_{t}$ are the initial and lag soil moisture time series, respectively, for the sample number $T$. The terms $\bar{x}$ and $\bar{y}$ are the corresponding mean soil moisture. In this study, setting the 


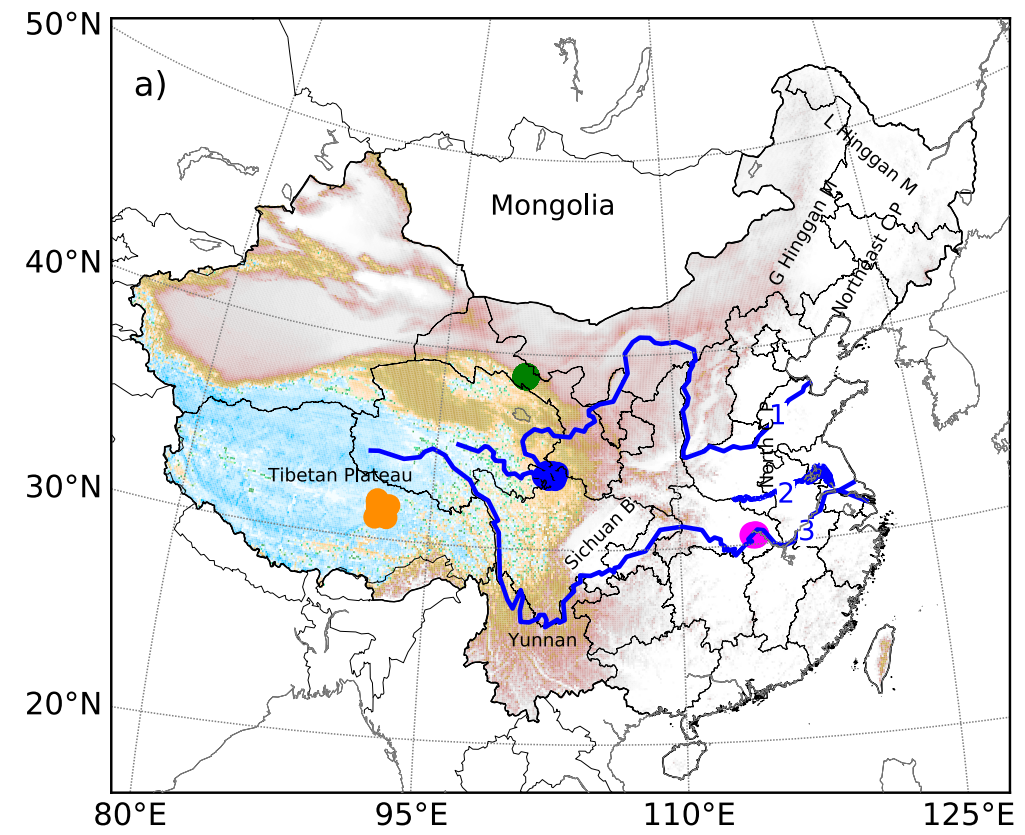

1 Yellow River

2 Huaihe River

3 Yangtze River
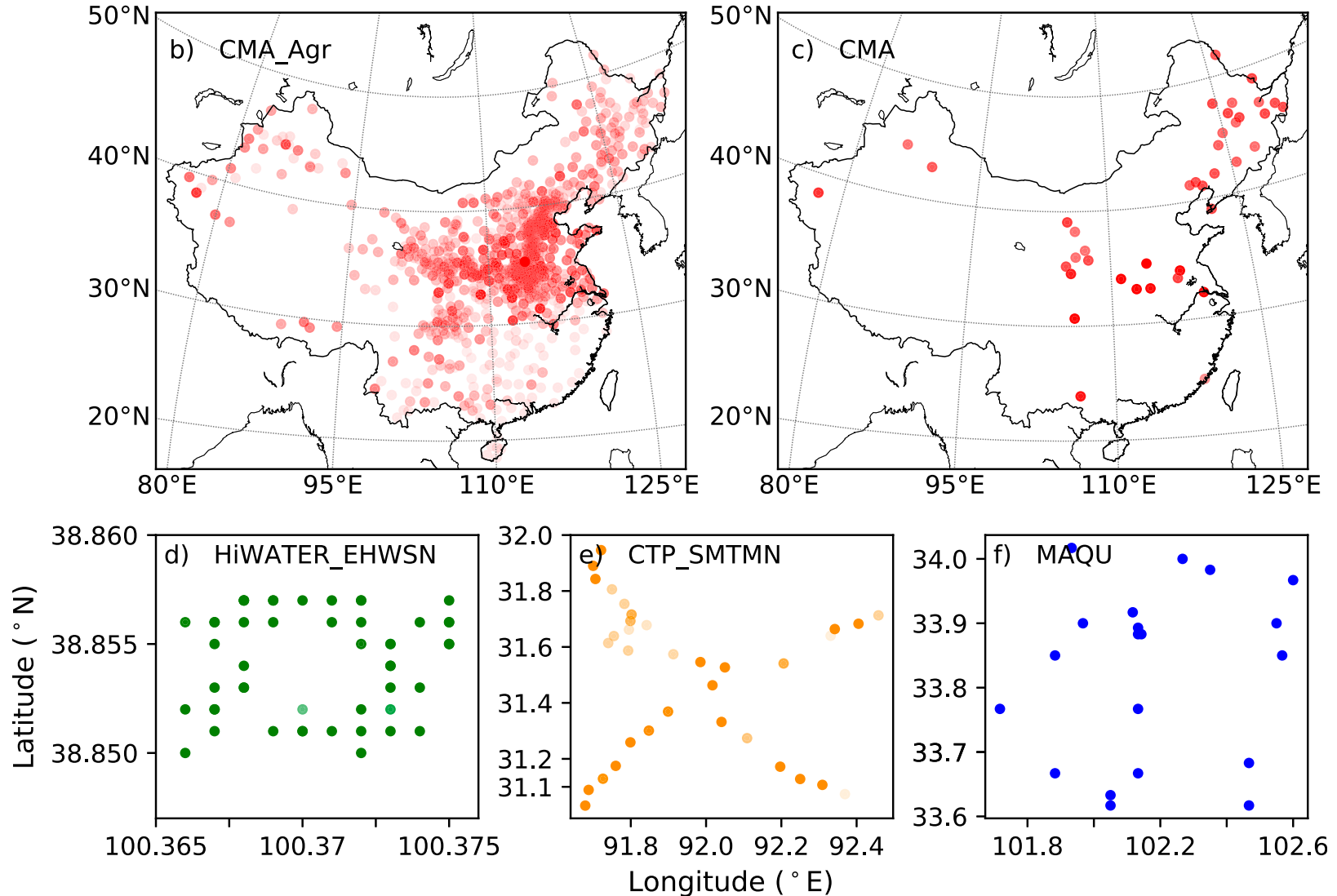

FIG. 1. (a)-(f) Geographical distribution of sites in six observational networks in China. Two nationwide networks shown in (b) and (c) and three of the four specific networks in (a) are magnified in (d)-(f). The SW-WHU includes only three sites that are close to each other. The transparency of colored dots in (b)-(f) denotes the sample size of the observations for each site. 
a)

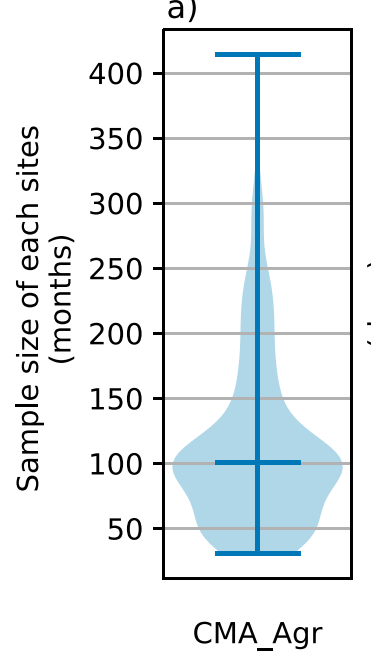

b)

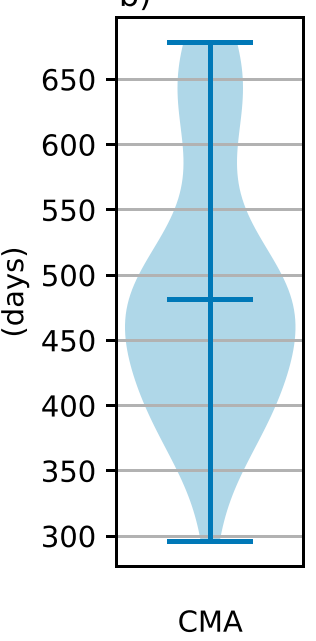

c)

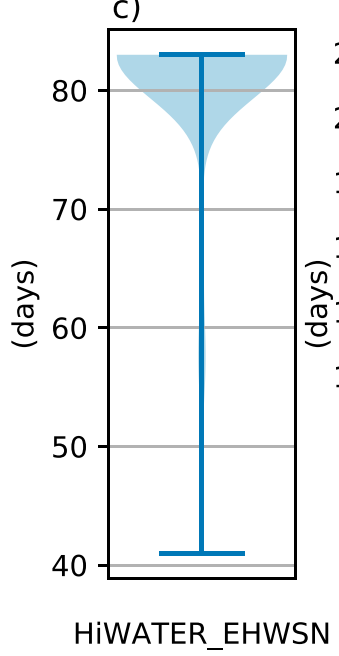

d)

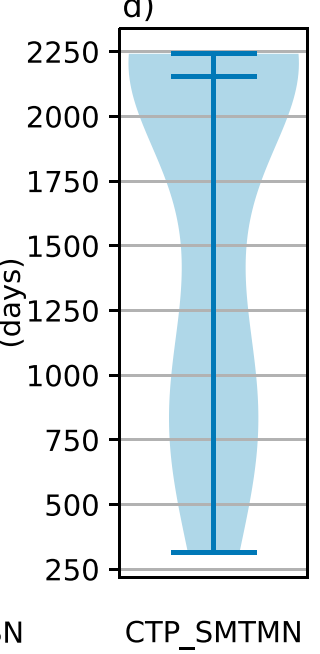

e)

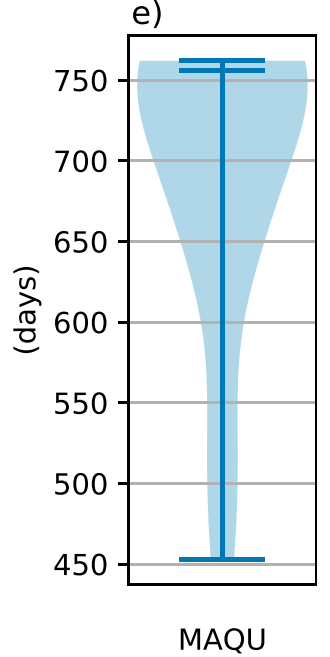

FIG. 2. (a)-(e) Distributions of the numbers (months or days) of observations for all sites within five observational networks. Horizontal lines represent the maximums, medians, and minimums of sample sizes. The values of the maximum and median are both 83 in (c).

lag time step to one day, lag autocorrelation is calculated iteratively until the autocorrelation drops below the value at the $95 \%$ significance level for a one-tailed test with no fewer than 30 samples. The number of days to reach decorrelation is referred to as the persistence time scale. Here, the correlation cutoff is set at 0.37 , which ensures that all correlations are significant at the $95 \%$ significance level (for $n \geq 30$ ); hence, the time scales of soil moisture persistence are statistically significant over its specific timeframes. If the lag time series contains fewer than 30 samples but the autocorrelation is still greater than 0.37 , persistence days are estimated using $e$-folding time, as described by Eq. (4), according to the first-order Markov property in soil moisture processes (Delworth and Manabe 1988, 1989):

$$
r_{t}=\exp (-t / D)
$$

where $r_{t}$ is the autocorrelation at lag $t$ (e.g., 60 or 365 days) and $D$ is the $e$-folding days of anomalies in the absence of forcing. Thus, the estimation of persistence relaxes the limitation of a strict assumption of exponential decay of autocorrelations with the lag time and enhances the statistical significance constraint. To dampen the effect of the seasonal cycle in soil moisture on its autocorrelation, the annual cycle is removed by subtracting the 40-yr mean daily soil moisture. D'Agostino's chi-squared tests (D'Agostino 1971) are then applied to the anomalies, and the results suggest that daily anomalies are normally distributed, (e.g., for 0-28- and 0-100-cm soil layers, Stat $=1.04,0.95 ; p=$ $0.59,0.62>0.05=\alpha$, fail to reject $\left.H_{0}\right)$, consistent with observation-based soil moisture data (e.g., Bell et al. 1980; Li and Kawano 1996; Ryu and Famiglietti 2005). In this study, the focus is on intra-annual persistence using intra-annual soil moisture data, denoting the time, in terms of probability, that soil moisture tends to be invariable in a wet/dry state or dissipates/recovers from a wet/dry state. The calculation is mainly based on the coupling metrics toolkit, an open-source code package in FORTRAN, provided by Santanello et al. (2018).

\section{2) SEASONAL TREND DECOMPOSITION FOR INTEGRATED SOIL MOISTURE}

To examine the multiscale periodicity and long-term trends in the reanalysis soil moisture data at a regional scale, the integrated soil moisture series are generated by averaging the soil moisture over sites or corresponding grid cells along their time axes for both observations and reanalysis in two networks CMA and CMA_Agr, and then the integrated series are decomposed using the seasonal trend decomposition based on local regression (LOESS; Cleveland et al. 1990) in an additive model (STL) as in Eq. (5):

$$
Y_{t}=T_{t}+S_{t}+R_{t}, \quad t=1,2, \ldots, N,
$$

where the integrated soil moisture $Y_{t}$ is decomposed into longterm $T_{t}$, seasonal $S_{t}$, and the remaining $R_{t}$ components at time $t$. The long-term linear trend can then be separated from the long-term component by least squares linear regression, and the remainder of the nonlinear signal manifests repeated but nonperiodic long-term variability. The seasonal term represents variations over a fixed period (e.g., monthly), and the residual component contains subseasonal signals (e.g., daily) and noise other than the seasonal and long-trend components. By seasonal trend decomposition, the periodic signals in ERA5 soil moisture can be verified on daily, seasonal, and secular scales, which contribute to the persistence of soil moisture. The key method in STL decomposition is LOESS smoothing using a weighting function in which the influence of a neighboring value on the smoothed value decreases with distance. The weighting function $w\left(x_{k}\right)$ is defined as follows:

$$
w\left(x_{k}\right)=\left(1-\left|\frac{x_{i}-x_{k}}{d_{i}}\right|^{3}\right)^{3}, \quad k=1,2, \ldots, N,
$$

where $d_{i}$ is the distance from $x_{i}$ to the $k$ th neighboring point in a time series $x$. Then, LOESS is used to perform regression smoothing by a quadratic function whose coefficients are calculated by minimizing the following function: 


$$
\hat{y}_{k}=a+b x_{k}+c x_{k}^{2}
$$

If limited observations are available for estimating the linear regression function, the robust weightings $G\left(x_{k}\right)$ are calculated by estimating the residuals of the values up to this point and the resulting median, using the following formula:

$$
G\left(x_{k}\right)=\left\{\begin{array}{c}
\left\{1-\left[\frac{\left|y_{i}-\hat{y}_{i}\right|}{6 \operatorname{median}\left(\left|y_{i}-\hat{y}_{i}\right|\right)}\right]^{2}\right\}^{2}\left|\frac{y_{i}-\hat{y}_{i}}{6 \operatorname{median}\left(\left|y_{i}-\hat{y}_{i}\right|\right)}\right|<1 \\
0 \\
\left|\frac{y_{i}-\hat{y}_{i}}{6 \operatorname{median}\left(\left|y_{i}-\hat{y}_{i}\right|\right)}\right| \geq 1
\end{array} .\right.
$$

The robust weightings, multiplied with the proximity weightings [Eq. (6)], are used for re-estimating a linear regression function for the smoothed values $y_{s k}$ :

$$
y_{s k}=\sum_{k} w\left(x_{k}\right) G\left(x_{k}\right)\left(y_{k}-a-b x_{k}-c x_{k}^{2}\right)^{2} .
$$

By detrending, cycle-subseries smoothing, low-pass filtering, detrending of smoothed cycle subseries, deseasonalizing, and trend smoothing steps, the STL iteratively updates the seasonal and trend components and weights. Then, the remainder is

$$
R_{t}=Y_{t}-T_{t}-S_{t}
$$

The rigorous mathematical deduction can be found in the literature (Cleveland 1979; Cleveland et al. 1990).

\section{3) DEFINITION OF DRYLANDS USING AN ATMOSPHERIC INDICATOR AND SOIL MOISTURE}

Taking dryland expansion as an example, to investigate the implications of changed soil moisture persistence for terrestrial environments, drylands are defined using both an atmospheric indicator and soil moisture. The atmospheric aridity index (AI), the ratio of total annual precipitation to potential evapotranspiration, is used to determine dryland regions. According to Middleton and Thomas (1992), the regions with $\mathrm{AI} \leq 0.65$ are identified as drylands. The movement of the boundary line at $\mathrm{AI}=0.65$ indicates the expansion/contraction of drylands driven by atmospheric processes. Likewise, the soil moisture $\left(0.26 \mathrm{~m}^{3} \mathrm{~m}^{-3}\right.$ in the root layer $)$ coincident with the line of $\mathrm{AI}=$ 0.65 is used as another criterion to define drylands; similarly, the changes in drylands based on soil moisture are measured by its boundary line movements. Considering plant activities, comparisons between the areal changes in the drylands by AI and soil moisture are performed over the main growing season (May-September). In addition, the arid, transition, and humid climate zones are also defined, according to $\mathrm{AI}(\mathrm{AI}<0.2,0.2 \leq$ $\mathrm{AI} \leq 0.65$, and $\mathrm{AI}>0.65$, respectively), to assess soil moisture and its persistence changes in China.

\section{4) STATISTICS AND TESTS FOR ANALYSIS}

The other statistics used include the Pearson correlation coefficients [the same as Eq. (3)]. Given that it remains a challenge for most land models to concurrently capture the annual cycles in observed soil moisture in various layers, the correlation coefficients are estimated using the anomalies of daily/monthly soil moisture (raw data minus their mean) at the site-grid scale, thereby retaining the effects of the annual cycle. According to D'Agostino's chi-squared test, when a soil moisture time series is nonnormal, the Box-Cox power transformation (Box and Cox 1964) is carried out to reduce its nonnormality, and the transformation of soil moisture series SM has the following form:

$$
\operatorname{SM}(\lambda)=\left\{\begin{array}{l}
\frac{\mathrm{SM}^{\lambda}-1}{\lambda}, \lambda \neq 0 \\
\log (\mathrm{SM}), \lambda=0
\end{array},\right.
$$

where $\lambda$ is estimated by maximizing the log-likelihood function. The significance of correlations is tested according to the hypothesis test. The formula for the test statistic is

$$
t=r \sqrt{n-2} / \sqrt{1-r^{2}}
$$

where $r$ is the correlation coefficient, and $n$ is the sample size. The probability value $p$ is then computed using a $t$ distribution with $n-2$ degrees of freedom. As the $p$ is less than the significance level (e.g., 0.05), the correlation coefficient is significant. In addition, the standard deviation $s$ of a soil moisture series is computed as in Eq. (13):

$$
s=\sqrt{\frac{1}{n-1} \sum_{i=1}^{n}\left(x_{i}-\bar{x}\right)^{2}},
$$

where $n$ is the sample size, $x_{i}$ is the soil moisture series, and $\bar{x}$ denotes the mean soil moisture. The formula for the rootmean-square error (RMSE) is

$$
\mathrm{RMSE}=\sqrt{\frac{\sum_{i=1}^{n}\left(x_{\mathrm{ERA}}-x_{\mathrm{obs}}\right)^{2}}{n}},
$$

where $n$ is the sample size and $x_{\mathrm{ERA}}$ and $x_{\mathrm{obs}}$ are the ERA5 reanalysis and observational soil moisture, respectively. In addition, the linear trends are calculated using a least squares linear regression, and two-sided $p$ for a hypothesis test of significance is calculated with the $t$ distribution of the test statistic.

\section{Results}

\section{a. Fidelity of the ERA5 soil moisture against in situ observations}

The fidelity of the ERA5 soil moisture is evaluated using observational soil moisture at 956 sites within six networks in China, on daily, monthly, seasonal, and secular time scales during 1981-2016. The statistical analyses show that on the daily scale (Fig. 3a), the correlation coefficients at 114 out of the148 sites are significant ( $p<0.05$ ), accounting for $77 \%$, and the correlations at 53 sites are over 0.5 up to $36 \%$. Note that the depths of the soil layers vary with the network, especially at 0-100 cm for the network CMA (Table 1). For the CTP_SMTMN network, on the Tibetan Plateau, the mean correlation is 0.65 in the $0-28$-cm soil layer ( $p<0.01$, mean $n=1639$ ), and the maximum reaches 0.85 . Another network MAQU on the plateau shows a mean correlation coefficient of 0.48 ( $p<0.01$ with 

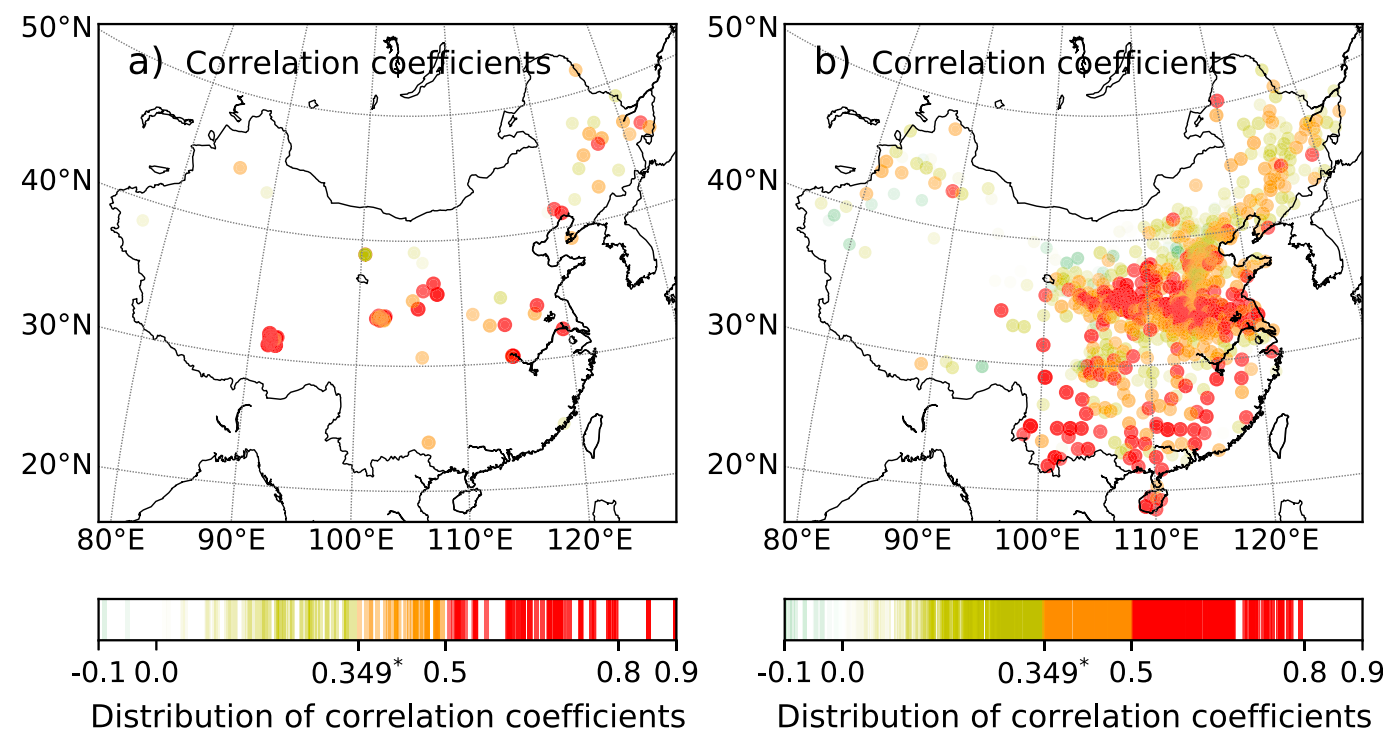

FIG. 3. Geographical distribution of correlation coefficients between ERA5 and observational soil moisture data, with the various sample sizes for each site (see Table 1, Figs. 1 and 2) over the years 1981-2016. (a) Networks 1-5 at a daily time interval and (b) network 6 at a monthly time interval (Table 1). The colored bars denote the distribution of the correlation coefficients, and the value of 0.349 indicates a significant correlation $(p<0.05)$ at the minimum sample size $(n=30)$.

mean $n=695$ ) with a maximum of 0.62 in the $0-7$-cm soil layer. These observations monitor the dynamics of only liquid soil water and hence include the effects of soil freeze-thaw cycles and the monsoon climate of the Tibetan Plateau (rainy season from June to August, dry season from December to April) (Yang et al. 2013). The annual variations in the observed soil moisture are enhanced by overlapping freeze-thaw cycles, but in ERA5, the total soil moisture is not influenced by these cycles. Their high correlations indicate that the reanalysis soil moisture data vary in phase with the wet-dry cycles in the observations. On the monthly scale (Fig. 3b), ERA5 can generally depict the observed soil moisture variations and geographical patterns. The correlations are significant at 673 sites $(p<0.05)$ of the 808 total sites, reaching $83 \%$, and the percentage is $27 \%$ for correlations greater than 0.5 in the $0-28-\mathrm{cm}$ soil layer. In summary, the significant correlations are widely distributed among various sites and at soil depths from 5 to $100 \mathrm{~cm}$, along with their large sample sizes $(n>30)$, ensuring the robustness of the statistics and their reasonable representativeness in space. The low correlations are largely due to mismatches between observational sites and model grid cells in terms of land cover type, soil type and the associated properties, which can exert a significant influence on the phaseshifting and timing of soil moisture variability (Wu et al. 2002; Albergel et al. 2012).

To limit the effects of scale mismatch between sites and grid cells, the site-averaged soil moisture for each network is compared further (Fig. 4). The results suggest that ERA5 also reasonably captures monthly and annual soil moisture dynamics, especially in the CMA, CTP_SMTMN, and CMA_Agr networks (Figs. 4a,b,f), with correlation coefficients of 0.65 , 0.71 , and $0.72(p<0.01)$, respectively. In the network CMA (with a depth of $0-100 \mathrm{~cm}$ ), the reanalysis agrees well with observations, especially in terms of amplitudes, with both having standard deviations of $0.02 \mathrm{~m}^{3} \mathrm{~m}^{-3}$, although the ERA5 shows a higher mean soil moisture than observations ( 0.29 and $0.27 \mathrm{~m}^{3} \mathrm{~m}^{-3}$ for the ERA5 and observations, respectively). Again, for the CTP_SMTMN and MAQU networks (with depths of 0-28 and 0-5 cm, Figs. 4b,d), which are located on the Tibetan Plateau, the observed liquid soil moisture shows larger annual variations (amplified by soil freeze-thaw cycles) than the total soil water in the reanalysis. This mechanism largely accounts for the discrepancies in standard deviations ( 0.07 and $0.04 \mathrm{~m}^{3} \mathrm{~m}^{-3}$ for observations and ERA5 in CTP_SMTMN and 0.13 and $0.03 \mathrm{~m}^{3} \mathrm{~m}^{-3}$ for MAQU) on the Tibetan Plateau. Nevertheless, ERA5 captures the observed phase shifts over time with high consistency. In the CMA_Agr network (with a depth of $0-28 \mathrm{~cm}$, Fig. $4 \mathrm{f}$ ), the dynamics of the ERA5 soil moisture data also agree well with those of observations, with a correlation of $0.72(p<0.01)$, despite the higher mean soil moisture of the ERA5 dataset than of the observations, analogous to the biases in deeper soil $(0-100 \mathrm{~cm})$ in the network CMA (Fig. 4a). In the other two networks (Figs. 4c,e), though with limited durations, agreement can still be observed in the main variations between the two soil moisture datasets.

Aiming to further assess the ERA5 soil moisture data on seasonal and secular time scales, a seasonal trend decomposition [section $2 b(2)$ ] is performed for site-integrated soil moisture time series in the $0-100-$ and $0-28-\mathrm{cm}$ soil layers in networks CMA and CMA_Agr, respectively, which have extensive spatial and temporal coverages. The decomposed seasonal cycles (Fig. 5 with statistics in Table 2) show that ERA5 encouragingly reflects the seasonality in the observed soil moisture, with correlations over $0.8(p<0.01)$. The residual 

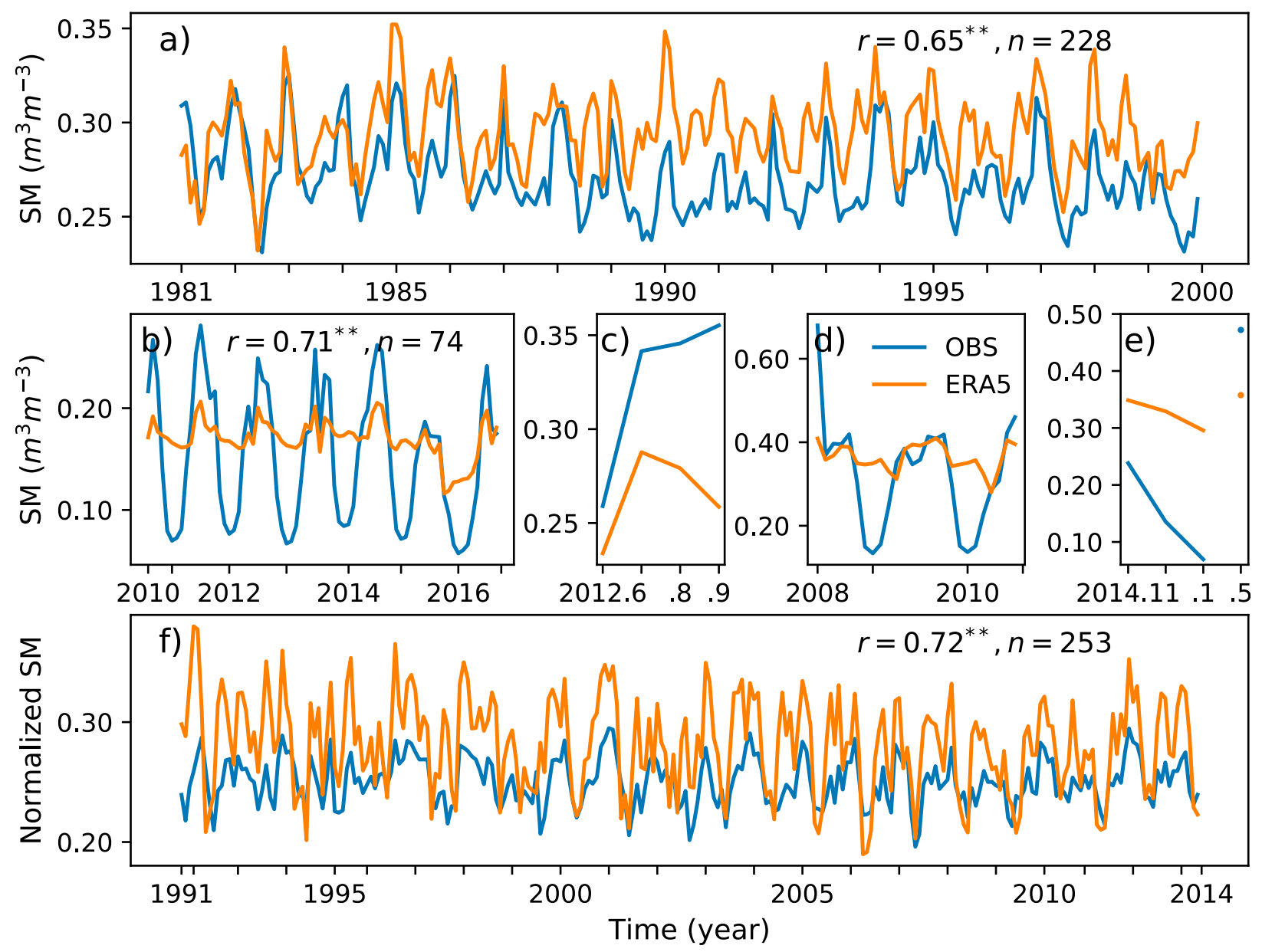

FIG. 4. Comparisons of network averaged time series for the ERA5 and observational monthly mean soil moisture. Networks of (a) CMA, (b) CTP_SMTMN, (c) HiWATER_EHWSN, (d) MAQU, (e) SW-WHU, and (f) CMA_Agr; $r$ is the correlation coefficient, and ** denotes significance at $p<0.01$ with sample size $n$.

terms, mainly representing the month-to-month variations, also show good agreement with each other, with correlations over $0.6(p<0.01)$. On annual and long-term time scales, although remarkable wet biases can be observed in the ERA5 soil moisture dataset (Figs. 5b,f), it still captures the observed variations in the 0-28-cm soil layer (CMA_Agr) but substantially overestimates the standard deviation and long-term trend (Table 2). In contrast, in the deeper 0-100-cm soil layer, the ERA5 soil moisture dataset shows decreased skill on interannual scales and underestimates the observed long-term trend. The decorrelation is directly induced by the lower persistence of long-lasting anomalies in the reanalysis soil moisture dataset, which is mainly associated with the ERA5 soil hydrological representations, e.g., the assumption of free drainage at the soil bottom and the inaccuracy of soil property data (Balsamo et al. 2011, 2015). This inaccuracy also contributes to the wet soil moisture biases in ERA5 by reducing bare soil evaporation. Additionally, the soil hydrology properties, allowing soil moisture to go lower than the wilting point in dry times, partly account for the large amplitudes of seasonal and interannual dynamics in the $0-28$-cm soil layer (Balsamo et al. 2015).

In summary, the above results, along with previous validations of the HTESSEL-simulated soil moisture for various regions (e.g., Balsamo et al. 2011, 2015; Li et al. 2020), confirm that ERA5 can reasonably represent the evolution of soil moisture observed in situ in China on daily to annual time scales. Therefore, the use of ERA5 soil moisture data in soil moisture persistence studies is justified. Furthermore, the uncertainties in soil moisture and its evaluations are discussed in section 4 .

\section{b. Spatial patterns of soil moisture persistence}

The intra-annual soil moisture persistence estimated using daily lag autocorrelation (365 days averaged from 1979 to 2018 ) in three soil layers (0-28-cm upper layer, 0-100-cm root layer, and 100-289-cm lower layer) shows that the persistence increases with soil depth from the upper to root to lower soil layers, especially in the northwestern arid zone (Fig. 6). From the perspective of climate zones, the statistics (Table 3) show 

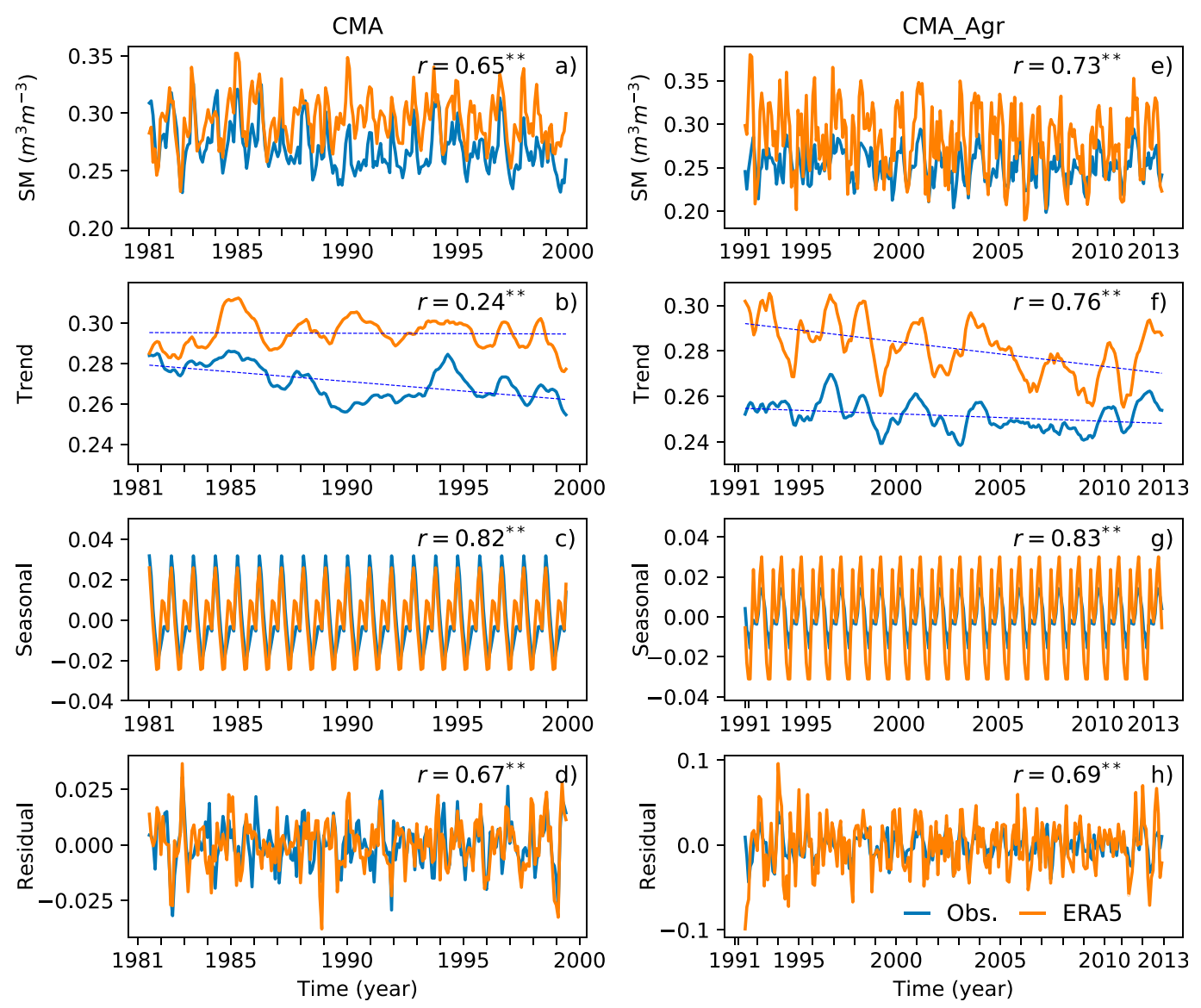

FIG. 5. Seasonal trend decomposition for integrated monthly soil moisture at all 40 sites of the network CMA and 808 sites of the network CMA_Agr and corresponding ERA5 reanalysis data for the 0-100- and 0-28-cm soil layers; $r$ denotes the correlation coefficient, and ** denotes significance at $p<0.01$ with sample sizes $n=228$ and 253 in networks CMA and CMA_Agr, respectively.

that persistence in the arid zone is 13 and 15 days in the upper and root layers, respectively, and up to 104 days in the lower layer. Likewise, the persistence increases vertically, with values of 19,25, and 60 days on average in the upper, root, and lower layers, respectively, in the humid zone. In between is the increase with depth in the transition zone. The maximum persistence (over 180 days) occurs in the lower layer in arid regions, and the increase is remarkably stronger than that in

TABLE 2. Statistics for seasonal trend decomposition analyses of the ERA5 and observational soil moisture (Fig. 3). Two asterisks (**) denote significance at the $p<0.01$ level.

\begin{tabular}{|c|c|c|c|c|}
\hline \multirow[b]{2}{*}{ Statistics } & \multicolumn{4}{|c|}{ Two observational networks of soil moisture } \\
\hline & \multicolumn{2}{|c|}{ CMA $(0-100 \mathrm{~cm}, n=228)$} & \multicolumn{2}{|c|}{ CMA_Agr $(0-28 \mathrm{~cm}, n=253)$} \\
\hline \multirow{4}{*}{$\begin{array}{l}\text { Correlation coefficients between ERA5 } \\
\text { and obs }\end{array}$} & Means & $0.65^{* *}$ & Means & $0.73 * *$ \\
\hline & Trends & $0.24 * *$ & Trends & $0.76^{* *}$ \\
\hline & Seasonal & $0.82 * *$ & Seasonal & $0.83^{* *}$ \\
\hline & Residual & $0.67 * *$ & Residual & $0.69 * *$ \\
\hline \multirow[t]{4}{*}{ Standard deviation $\left(\mathrm{m}^{3} \mathrm{~m}^{-3}\right)$, ERA5/obs } & Means & $0.021 / 0.021$ & Means & $0.039 / 0.019$ \\
\hline & Trends & $0.007 / 0.008$ & Trends & $0.012 / 0.006$ \\
\hline & Seasonal & $0.015 / 0.015$ & Seasonal & $0.019 / 0.009$ \\
\hline & Residual & $0.011 / 0.01$ & Residual & $0.030 / 0.015$ \\
\hline \multirow[t]{4}{*}{ Root-mean-square error $\left(\mathrm{m}^{3} \mathrm{~m}^{-3}\right)$} & Means & 0.029 & Means & 0.042 \\
\hline & Trends & 0.026 & Trends & 0.031 \\
\hline & Seasonal & 0.009 & Seasonal & 0.013 \\
\hline & Residual & 0.009 & Residual & 0.023 \\
\hline $\begin{array}{l}\text { Linear trends }\left(\mathrm{m} 3 \mathrm{~m}^{-3} \text { decade }^{-1}\right), \\
\text { ERA5/obs }\end{array}$ & Trends & $-0.0004 /-0.0095 * *$ & Trends & $-0.0109 * * /-0.0033 * *$ \\
\hline
\end{tabular}



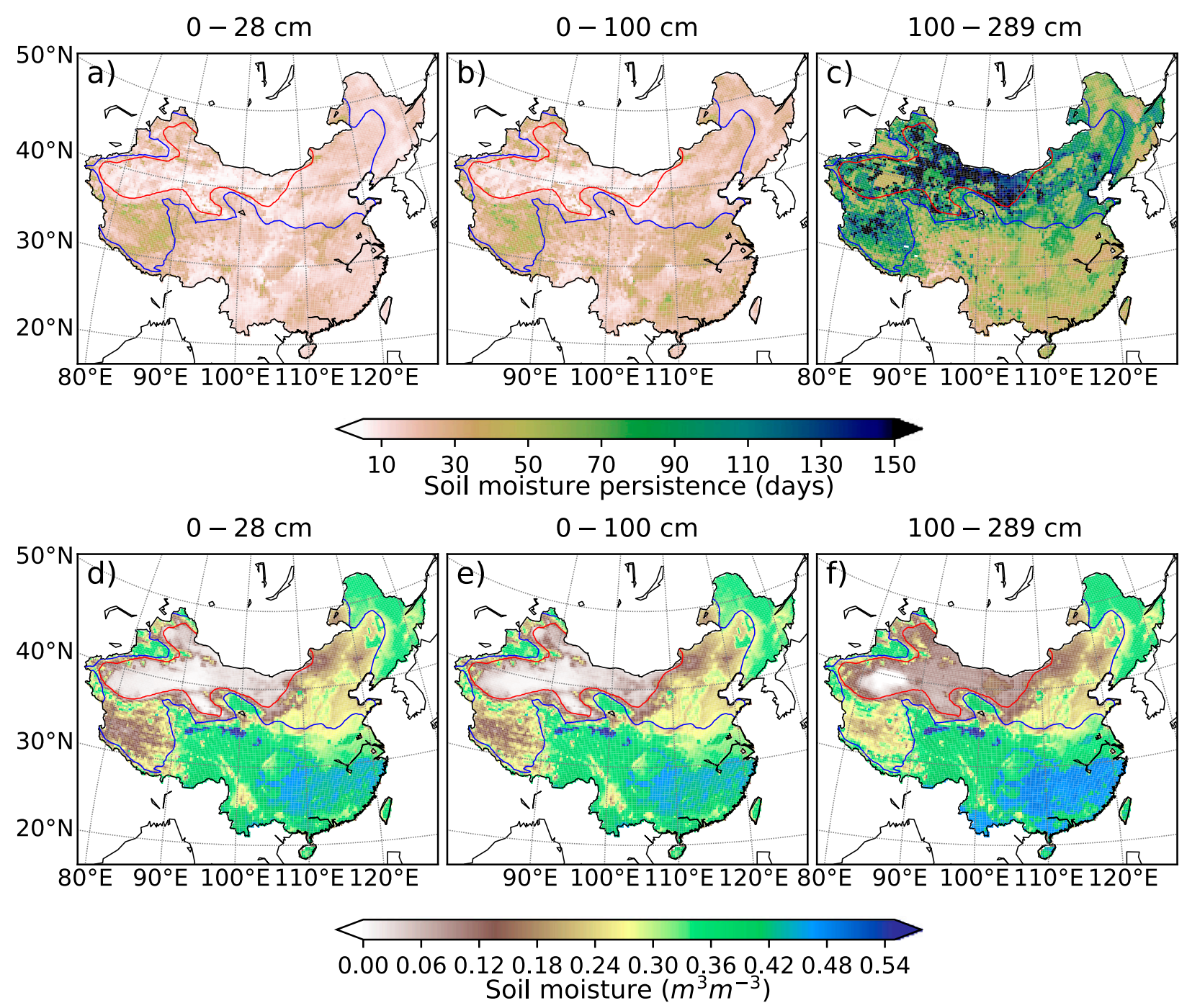

FIG. 6. Spatial patterns of mean intra-annual soil moisture persistence in three soil layers and corresponding daily mean soil moisture during 1979-2018. The red and blue lines are the contours of AI at 0.2 and 0.65 , respectively, denoting the arid, transition, and humid climate zones in China from northwest to southeast.

the soil moisture content. The long persistence in deep soil is spatially in good agreement with long-lasting soil droughts (over 12 months) in arid regions ( $\mathrm{Li}$ and $\mathrm{Ma} 2015$ ). In contrast, the relationships between soil moisture and its persistence (Fig. 7) suggest that persistence is fairly low in extremely dry or wet areas (with the scarce presence of soil moisture anomalies with small standard deviations or even close to zero), such as in parts of the extremely dry northwestern regions and the wet Yangtze River valley. There is a bell-shaped relationship between persistence and soil moisture content, with the longest persistence corresponding to moderate soil moisture with strong variations and shifting to the dry end in the deep soil layer, in agreement with the findings in a multimodel experiment (Seneviratne et al. 2006).

Regionally, shorter persistence can be observed in mountainous areas; for instance, there is a contrast between the
Greater and Lesser Hinggan Mountains and the Northeast China Plain. Such a spatial structure is also observed in Europe (Orth and Seneviratne 2013), reflecting the buffering effect of forests on soil moisture variations. On the Tibetan Plateau, the persistence shows an east-west disparity, which agrees with the findings from the Global Land Data Assimilation System (GLDAS; Yang and Wang 2019). These regional-scale characteristics point to the important roles of local vegetation, topography, and phase changes in soil moisture in reshaping the persistence of soil moisture.

\section{c. Seasonality of soil moisture persistence}

The seasonality of persistence is measured with the lag autocorrelation of daily soil moisture, covering approximately 90 days averaged from 1979 to 2018, in the three soil layers. Seasonal changes in persistence show clear evolutions with 
TABLE 3. Statistics for mean soil moisture and its persistence in the three climate zones during 1979-2018. SM denotes volumetric soil moisture, and SMP stands for soil moisture persistence (days).

\begin{tabular}{|c|c|c|c|c|c|c|c|c|c|}
\hline \multirow{2}{*}{$\frac{\text { Depths }}{\text { Climate zones }}$} & \multicolumn{3}{|c|}{$0-28 \mathrm{~cm}$} & \multicolumn{3}{|c|}{$0-100 \mathrm{~cm}$} & \multicolumn{3}{|c|}{$100-289 \mathrm{~cm}$} \\
\hline & Arid & Transition & Humid & Arid & Transition & Humid & Arid & Transition & Humid \\
\hline SM & 0.10 & 0.21 & 0.34 & 0.11 & 0.21 & 0.34 & 0.15 & 0.22 & 0.36 \\
\hline SMP & 13 & 19 & 19 & 15 & 23 & 25 & 104 & 92 & 60 \\
\hline
\end{tabular}

climate zones, and they are stronger in the transition zone than in the others, especially in the lower soil layer (Fig. 8). For instance, the seasonal changes range from 8 to 39 days for the three layers in the transition zone but from 5 to 31 and from 9 to 30 days in arid and humid zones, respectively (Table S1 in the online supplemental material). For the three climate zones, the maximum persistence occurs in winter in the upper and root layers but autumn in the lower layer, while in all layers, the minimum persistence tends to appear in summer. The largest relative increases from the upper to lower layers also occur in summer. The seasonality of persistence is mainly associated with the monsoon climate and with changes in soil properties and vegetation activities between the wetting and drying stages of the soil (Haines 1930; Hsiao and Acevedo 1974). In autumn in the transition zone, the increased persistence can last through winter, largely resulting from the freezing processes in the root layer, especially on the Tibetan Plateau and in northeastern China. In the lower soil layer, the lack of soil freezing at these depths partly contributes to the reduced persistence in winter. In southwestern China (e.g., Yunnan Province), longer persistence occurs in summer in the root layer, which is presumably due to the evolution of the southwestern monsoon rainfall.

\section{d. Decadal variability in soil moisture persistence}

Considering the periodic effects and accumulated biases of soil moisture climatology, the mean persistence values during four separate 5-yr periods with similar wet-dry climates, 198185, 1991-95, 2004-08, and 2014-18, instead of long-term linear regressions, are compared to assess the decadal variability. The persistence is also estimated with 365 daily anomalies derived by averaging over each 5 -yr period. The decadal changes (Fig. 9) are characterized by remarkable consistency in space among the periods of 1990s and 1980s (1991-95 minus 1981$85), 2010$ s and 2000s (2018-14 minus 2004-08), and the whole study period (2018-14 minus 1981-85), as well as clear regional footprints with decreases/increases in persistence on decadal scales in the three layers. For example, based on changes of longer than 1 day across China, the decreased persistence covers $4.89 \mathrm{Mkm}^{2}$, slightly larger than the area of increased persistence, $4.22 \mathrm{Mkm}^{2}$, in the root layer during the $2010 \mathrm{~s}$ relative to the $1980 \mathrm{~s}$, while increased persistence expanded by approximately $0.18 \mathrm{Mkm}^{2}$ in the lower soil, relative to the root layer, and by $0.57 \mathrm{Mkm}^{2}$ in the upper layer (Table S2). In terms of climate zones, the root layer persistence increased by 5 days on average in the western arid zone along $90^{\circ} \mathrm{E}$ longitude covering an area of approximately $0.4 \mathrm{Mkm}^{2}$, while in the eastern part, decreased persistence ( 3 days) occurred in an area of $0.43 \mathrm{Mkm}^{2}$ in the comparison between the $2010 \mathrm{~s}$ and $1980 \mathrm{~s}$. In the lower layer, the persistence increased (decreased) by 11 (16) days in smaller (larger) areas of $0.29 \mathrm{Mkm}^{2}\left(0.56 \mathrm{Mkm}^{2}\right)$ in the two regions (Tables S3 and S4). This east-west contrast between the 2010s and 2000s is similar to that between the 1990s and 1980s. In the transition zone, the Tibetan Plateau region shows an increase of 4 days in the root layer and an increase of 13 days in the lower layer. Furthermore, there is a decadal shift in the root layer from a decrease-dominated change in the 1990 s relative to the 1980 s to an increase-dominated change in the 2010 s relative to the 2000 s (Table S3). In the eastern part of this zone, the decadal changes in the root layer feature
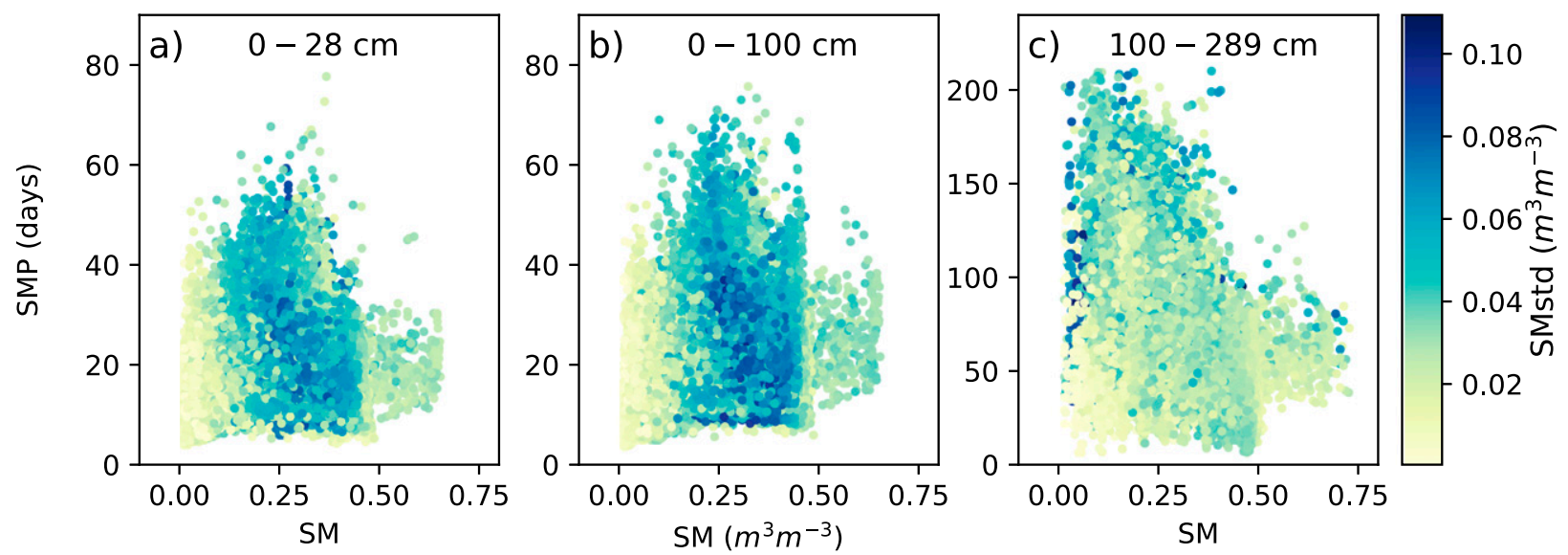

FIG. 7. Relationships between soil moisture persistence and soil moisture. SM denotes the mean soil moisture, SMstd denotes the soil moisture standard deviation, and SMP denotes soil moisture persistence. 


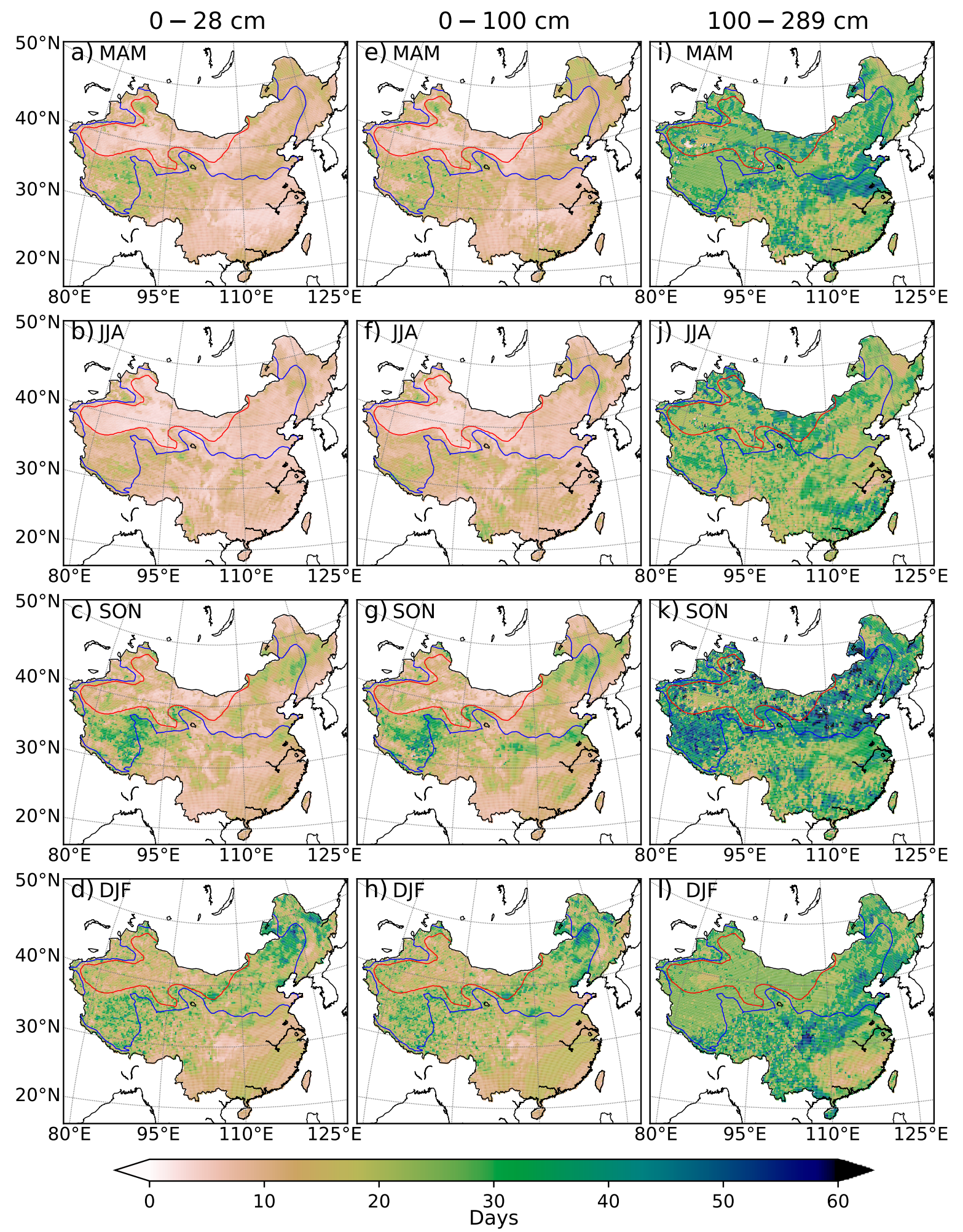

FIG. 8. Spatial patterns of seasonal variability in soil moisture persistence at three depths. (a),(e),(i) March-May (MAM); (b),(f),(j) June-August (JJA); (c),(g),(k) September-November (SON); and (d),(h),(l) December-February (DJF). The red and blue lines denote $\mathrm{AI}=0.2$ and 0.65 contours, respectively, indicating the arid, transition, and humid climate zones from northwest to southeast. 
1990s minus 1980s

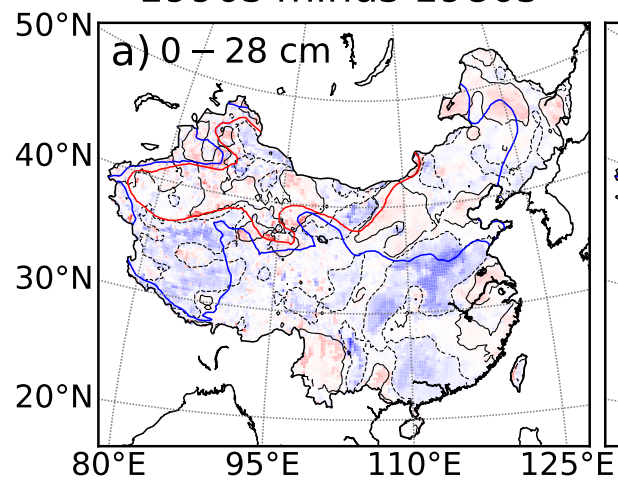

2010s minus 2000s

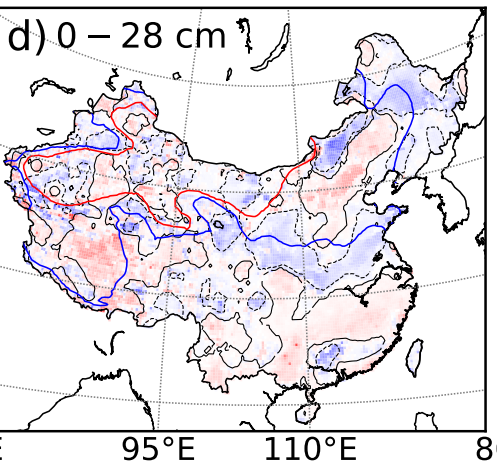

2010s minus 1980s

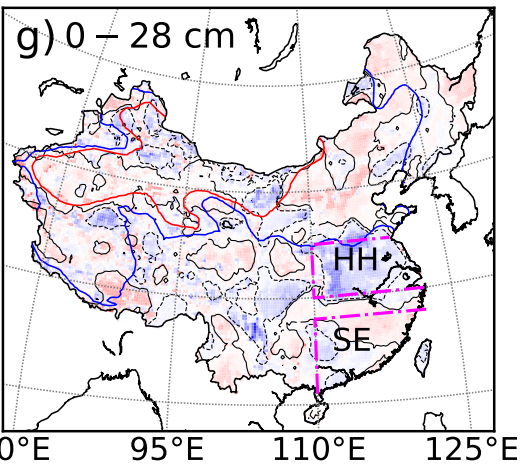

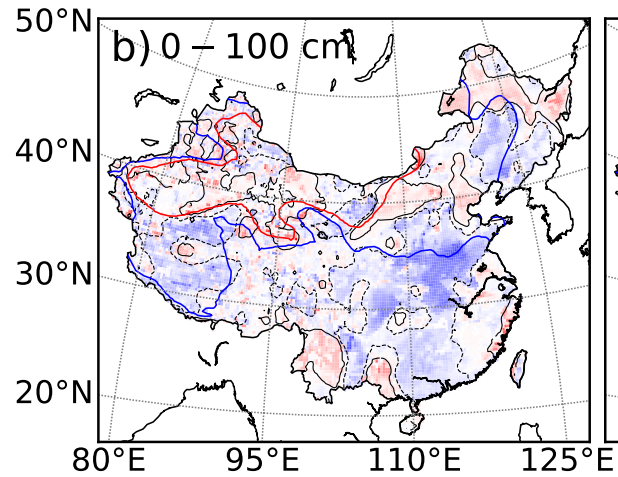
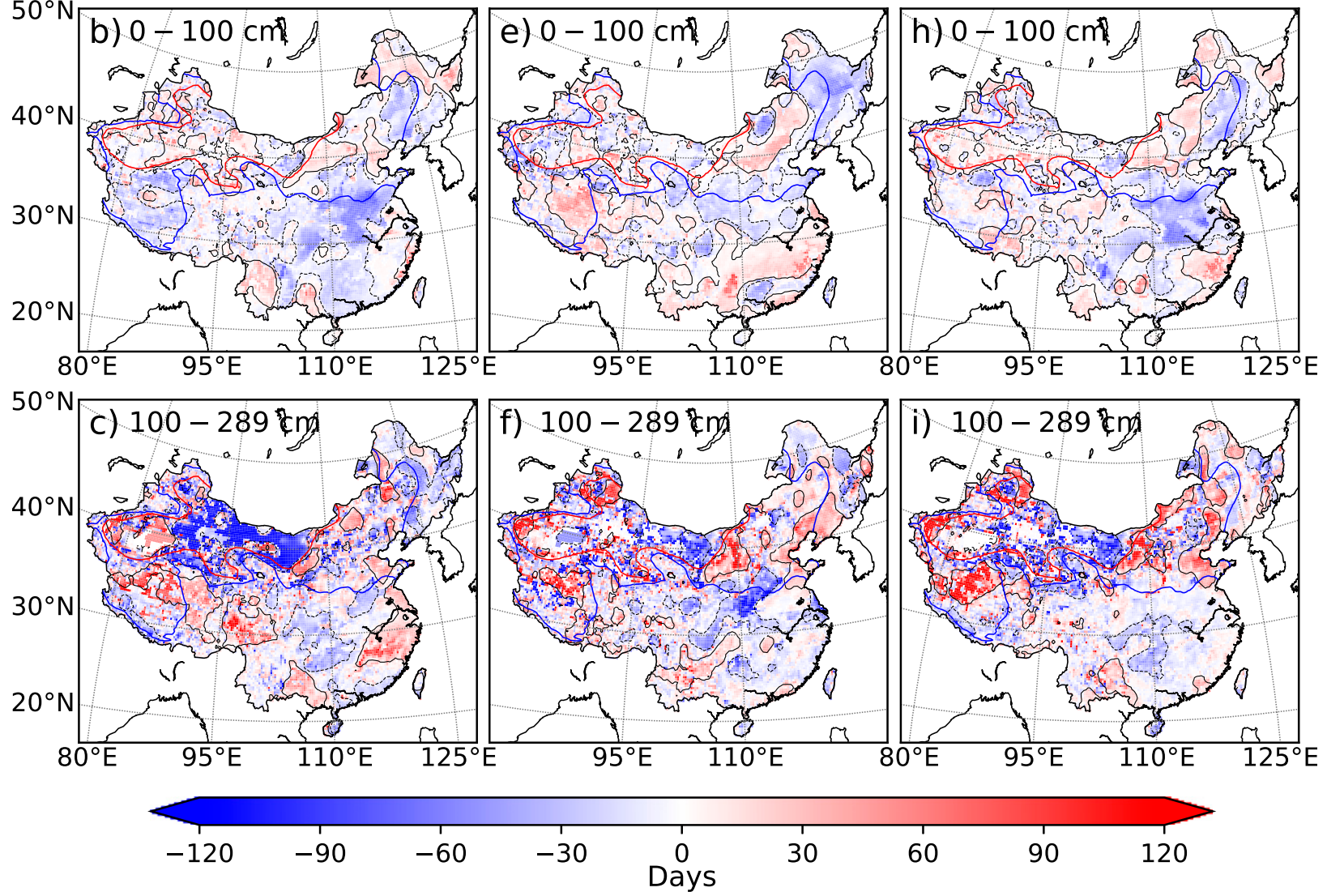

FIG. 9. Decadal differences in soil moisture persistence in the three soil layers. The 1980s denote persistence estimated using daily anomalies of averaged soil moisture for 1981-85 $(n=365)$; the 1990s, 2000s, and 2010s represent the same processing as the 1980s but for 1991-95, 2004-08, and 2014-18, respectively. The red and blue lines denote AI $=0.2$ and 0.65 contours, respectively, indicating the arid, transition, and humid climate zones from northwest to southeast. The black (dashed) lines denote the $30 \%$ variations in soil moisture persistence.

increase in the northwest and decrease in the southeast, with areas of 0.67 and $0.84 \mathrm{Mkm}^{2}$, and the decreased persistence expands toward the humid zone in northeastern China and the HuangHuai region (Table S4). However, such an expansion is not observed in the lower layer. In contrast, in lower soil, the increased persistence dominates this region, with areas of $0.92 \mathrm{Mkm}^{2}$ (Table S4). In the humid zone, there is a contrast in both the upper and root layers: a decrease in the humid Huang-Huai region $(\mathrm{HH}$ in Fig. 9g) and an increase in southeastern China (SE in Fig. 9g), with magnitudes of 24 and 3 days, respectively, and the contrast is reduced in the lower soil (Tables S3 and S4). Moreover, the increased persistence intensifies and expands in the lower soil layer, and this is the case in the western part of the humid zone as well.

In summary, during the 2010s in comparison with the 1980s, decadal persistence changes exhibit a contrast between an increase in the west and a decrease in the east in the three soil 
layers in the arid zone, and increases in persistence prevail across the transition zone with regional decreases in the southeast part of the eastern transition zone in all layers. The increases in the humid zone expand from the upper to the lower layer as the decreases spatially contract, e.g., in the Huang-Huai region. Discrepancies in persistence between the upper and lower layers can be seen along the transition zone, e.g., the Tibetan Plateau, Huang-Huai region, and northeastern China, where soil moisture also shows enhanced variations in the root layer (Fig. S1). Furthermore, quantile regression analyses reveal stronger variations at the high end of soil moisture persistence (figure not shown), which is in agreement with the increased soil moisture droughts ( $\mathrm{Li}$ and Ma 2015) in the regions.

\section{e. Seasonal contributions to decadal persistence variability}

The seasonal contributions to decadal persistence variability are investigated during the 2010s relative to the 1980s (2018-14 minus 1981-85), owing to the similarity between the decadal patterns. The seasonal changes show that strong variations generally occur in autumn and intensify with soil depth (Fig. 10). The regional mean changes in persistence (Table S5) indicate that the east-west contrast in the root layer in the arid zone starts in autumn owing to the decreases in the east and intensifies in winter because of the considerable increases in the west. In spring and summer, the contrast is reduced because of the similar increases in both regions. In the lower layer, a similar pattern appears in winter, is strongest in spring and disappears in summer. In the transition zone, the dominant changes also start in autumn in the root layer but in summer in the lower layer. In the humid zone root layer, e.g., the HuangHuai region and southeastern China, the decadal features of persistence changes are also shaped by autumn changes and persist throughout winter until spring. The enhanced changes in autumn persistence might influence the seasonal predictability of the regional climate, owing to long persistence per se or substantial soil moisture anomalies. In the eastern transition zone, the decreases in persistence in the root layer can contribute to recovery after droughts in autumn. However, once strong droughts propagate into the lower soil, their influence tends to persist considerably longer due to increased persistence in this layer. In contrast, in southeastern China, the persistence increases in summer and autumn in the upper soil layer but decreases in the lower layer, indicating the prolonged durations of anomalies (e.g., floods/droughts) in the upper soil layer but reduced durations of anomalies in the deep soil over the last decades. Note that soil moisture persistence based on lag autocorrelation is dependent on the length of the given time series, which tends to undervalue the seasonal contributions to decadal persistence variabilities. For example, there are no similarly large-scale seasonal persistence decreases compared to decadal variabilities in the upper and root layers in the Huang-Huai regions.

\section{Discussion}

\section{a. Possible mechanisms for the variability in soil moisture persistence}

Soil moisture persistence stems from land-atmosphere interactions. Its variability is jointly driven by atmospheric and land processes. Previous studies have identified several factors that regulate soil moisture persistence, e.g., initial soil moisture, subsequent atmospheric forcing, interactions between terrestrial hydrological processes (Delworth and Manabe 1988, 1989; Koster and Suarez 2001; Mahanama and Koster 2005; Seneviratne et al. 2006; Orth and Seneviratne 2012, 2013; MahfuzurRahman and Lu 2015; Gao et al. 2018; McColl et al. 2019), soil freeze/thaw, snowpack, and vegetation processes (Shinoda 2001; Liu 2010; Yang and Wang 2019). These findings have been confirmed by ground/satellite observations and by modeling studies, which fundamentally contribute to the understanding of possible mechanisms underlying the variability in soil moisture persistence.

Persistence increases from humid to arid regions, especially in the deep soil, and is characterized by a southeast-northwest gradient. This spatial pattern is in line with both observational and model-based patterns (Liu and Avissar 1999; Seneviratne et al. 2006), especially when interannual persistence is taken into account (Fig. 11). The spatial gradient might be interpreted via the following aspects: 1) Large-scale climate forcing. The monsoon establishes a moisture gradient from humid southeastern China to dry northwestern China. In dry regions, positive/negative soil moisture anomalies are mainly dissipated by evapotranspiration/rainfall, while in humid regions, they are dissipated by runoff/rainfall (Seneviratne et al. 2006). The high (low) precipitation frequency contributes to the quick (slow) dissipation of negative soil moisture anomalies in humid (arid) regions. In terms of positive anomalies, dissipation by evapotranspiration in arid regions is slower than that by runoff processes, owing to the hysteretic effects of the soil water retention curve (Haines 1930). On a large scale, the dissipation rate of soil moisture anomalies is tied to potential evaporation (Liu and Avissar 1999), which is smaller at high latitudes/ elevations than at low latitudes/elevations. Thus, the southnorth gradient of the dissipation rate contributes to shaping the pattern of soil moisture persistence. 2) Regional climate and vegetation processes. At high latitudes/elevations (e.g., on the Tibetan Plateau), soil anomalies are preserved as variations in the amount of soil ice and are carried into the next year, extending the persistence of anomalies by several months (Yang and Wang 2019). Additionally, the surface snow cover further prolongs the persistence of anomalies across northern China via snow hydrological effects (Matsumura and Yamazaki 2012). Vegetation processes, especially variations in root depth, may affect soil water flow and contribute to the persistence gradient owing to differences in species and properties (Shinoda 2001). In addition to the aforementioned factors, the other processes of land-atmosphere interactions might contribute to the formation of persistence patterns in China, and these contributors may vary with location and time.

Decadal variations in soil moisture persistence during 19792018 (Figs. 9 and 10) can be interpreted largely from the perspective of climate change and variability, as the changes in the properties of soil, topography, and land use and land cover are not explicitly considered in the ERA5 model system. With climate change, the land water cycle, as a component of Earth's climate system, has also been altered (Milly et al. 2005). Where the soil moisture goes into drying states or strengthening 

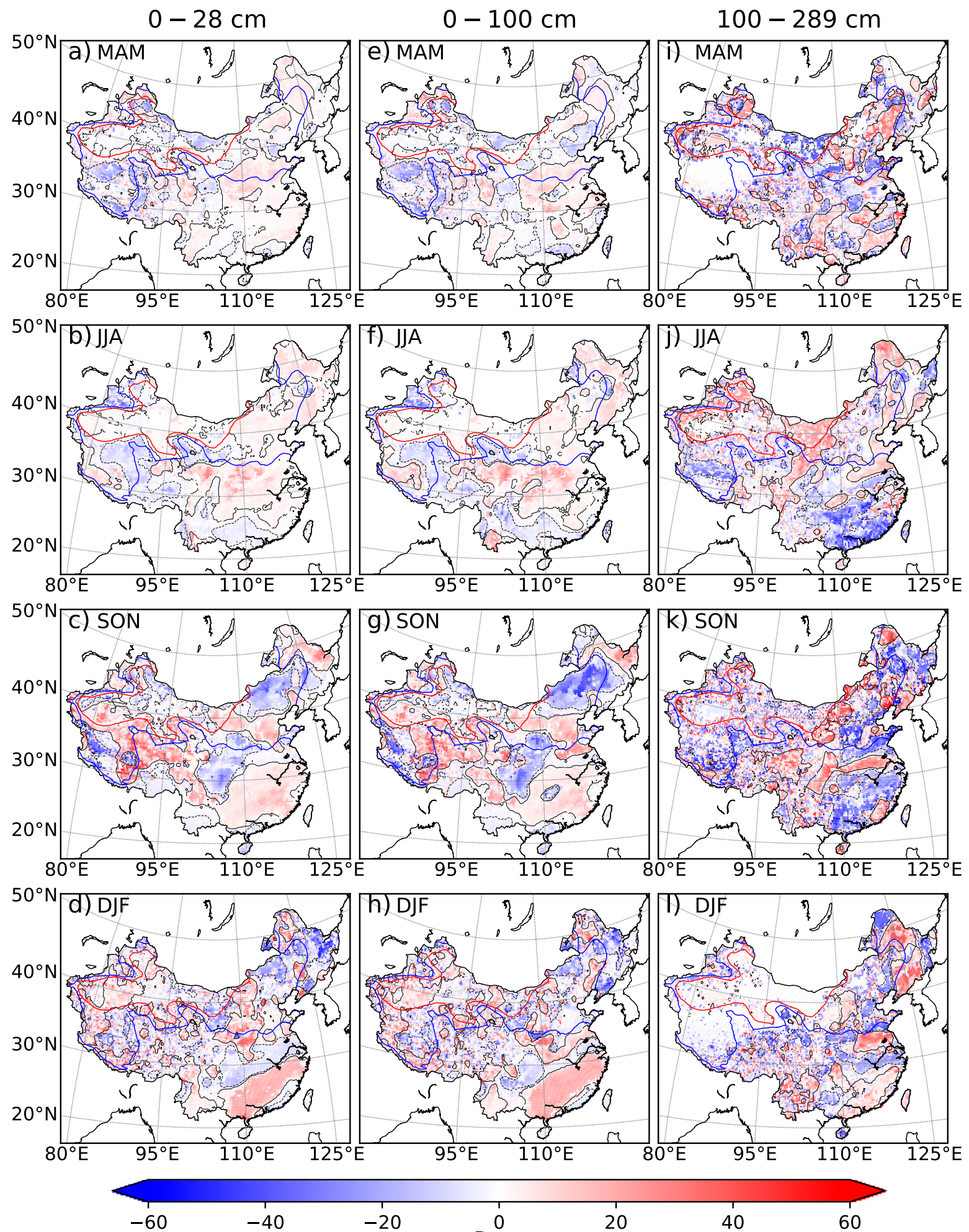

FIG. 10. Decadal differences in the seasonality of the soil moisture persistence in the three soil layers between the 2010s and 1980s. The 1980s and 2010s denote the same periods as in Fig. 9. March-May (MAM), June-August (JJA), September-November (SON), and December-February (DJF). The red and blue lines denote AI $=0.2$ and 0.65 contours, respectively, indicating the arid, transition, and humid climate zones from northwest to southeast. The black (dashed) lines denote the $30 \%$ variations. 


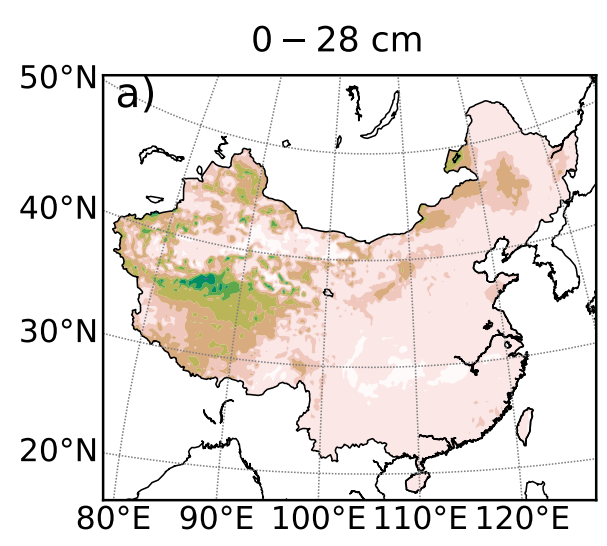

$$
0-100 \mathrm{~cm}
$$

$100-289 \mathrm{~cm}$

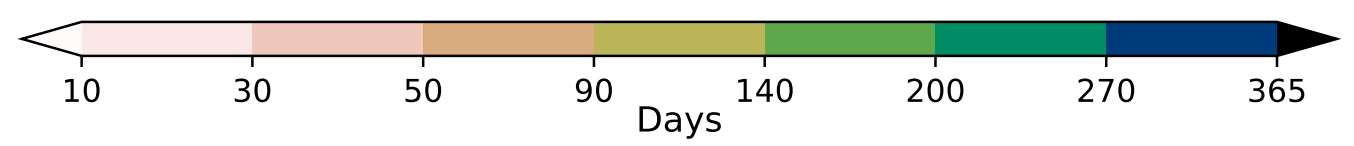

FIG. 11. Spatial patterns of mean soil moisture persistence based on a 5-yr time frame in the three soil layers. The estimation is conducted using 5-yr daily soil moisture anomalies $(n=1825)$ averaged during 1981-85, 1991-95, 2004-08, and 2014-18 in each of the three layers.

variations, soil moisture persistence tends to increase in these regions. For example, soil moisture persistence shows predominant increases across drylands, which may point to the intensified impacts of soil droughts and the expansion of dryland areas over the last four decades. The decreases in persistence in parts of the semiarid Tibetan Plateau indicate a substantial improvement in soil wetness.

In parts of the arid regions, precipitation increases significantly, as does the soil moisture; however, the absolute increases are not enough to change the soil moisture regime or to depress frequent negative soil moisture anomalies. On the central Tibetan Plateau, more convective precipitation is triggered as the surface air temperature increases (Yang et al. 2014). The increased precipitation leads to increases in the soil moisture, which greatly shortens the persistence of negative soil moisture anomalies, especially in the upper soil layer. The increases in soil moisture can also be indirectly confirmed by significant lake expansion and runoff increases (Lei and Yang 2017; Zhang et al. 2019). Nonetheless, the mechanisms still require more effort due to the fewer observations available at this point over this region.

In the humid Huang-Huai region and southern China with consistently high soil moisture, the increases in precipitation amount and frequency (Piao et al. 2009; Gu et al. 2017) assist in more quickly dissipating negative soil moisture anomalies, leading to decreases in persistence. Regarding positive anomalies in soil moisture, runoff processes can more rapidly drain water from wetter soil, dissipating anomalies in soil moisture. The increase in persistence across this region is largely regulated by changes in the precipitation regime; for instance, in 1960-2011, the observed amounts and frequencies of light and moderate rain in southeastern China significantly decreased, while heavy rain and rainstorms increased (Huang et al. 2015). The changed precipitation regime, along with increased evapotranspiration under warming conditions, reduces soil moisture and hence prolongs the persistence of soil moisture anomalies.
Reduced precipitation and, thus, significant soil moisture decreases $(p<0.05)$ largely account for the increase in persistence in southwestern China (e.g., Yunnan Province), which is consistent with the intensified droughts in recent decades (Yan et al. 2017).

Regarding the seasonality of variations in soil moisture persistence, owing to the monsoon climate in China, the soil generally absorbs water from rainfall in summer and releases water in autumn. An absorption depends on large soil pores, but desorption is governed by smaller pores, which results in a hysteretic effect between the absorption and desorption of soil water (Haines 1930). This process amplifies the variations in soil moisture anomalies in autumn.

\section{b. Implications of soil moisture persistence changes for terrestrial environments}

To understand the implications of changes in soil moisture persistence on terrestrial environments, taking drylands as an example, the variations from 1979 to 2018 in China are compared between estimates using the atmospheric indicator and soil layer soil moisture (Fig. 12). The geographic locations of the drylands and their changes are generally consistent between the estimates by the index AI and soil moisture. They both display a southeastward expansion of drylands in China; however, their intensities are substantially different. Based on AI, the expansion over the growing season (May-September) reaches $0.72 \mathrm{Mkm}^{2}$ in the $2010 \mathrm{~s}$ and increases by approximately $21.6 \%$ compared with the area in the 1980 s. However, based on soil moisture, the values are $0.50 \mathrm{Mkm}^{2}$ and $14.9 \%$. In the central Tibetan Plateau, according to the soil moisture criterion, the extensive dryland contraction detected by AI did not occur until the 2010s. Considering the possible periodicity of climate, dryland changes are further compared between the 1990s and 1980s (Fig. 13). The expansion is $12.5 \%$ and $3.2 \%$ based on AI and soil moisture, respectively, along with slight contractions in the central Tibetan Plateau. The directions of 

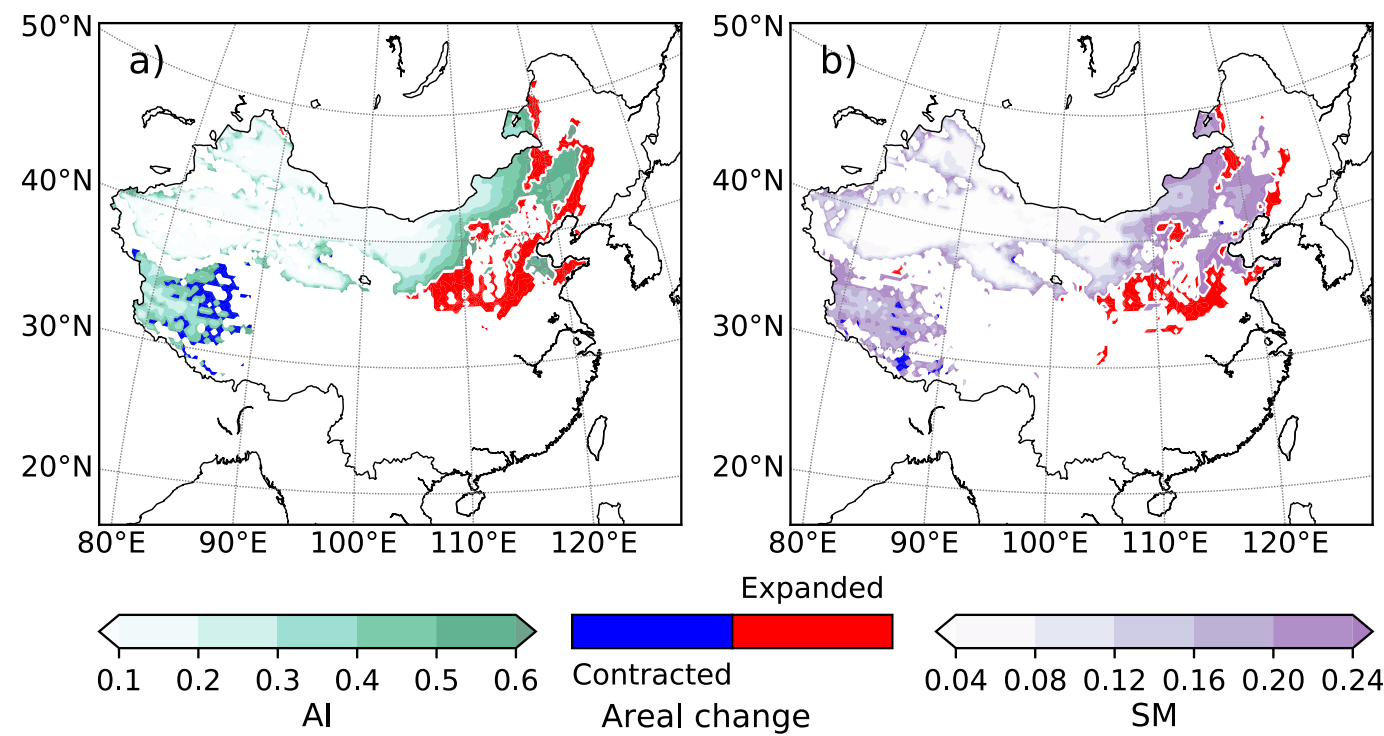

FIG. 12. Geographic distributions of drylands and their areal changes according to (a) AI and (b) soil moisture during growing seasons between the 2010s and the 1980s. AI denotes aridity index, the ratio of annual precipitation to evapotranspiration, and SM is soil moisture $\left(\mathrm{m}^{3} \mathrm{~m}^{-3}\right)$; the red and blue contours represent expanded and contracted regions of drylands during the 2010s relative to the 1980s, based separately on the AI and soil moisture metrics.

the dryland variations agree with those in the 2010s but with less intensity, highlighting the persistent southeastward expansion of drylands in China. The dryland expansion/contraction is consistent in space with the increases/decreases in the root layer soil moisture persistence during the main growing seasons, manifesting soil moisture regime changes in those regions. The comparisons illustrate the difference between soil dryness and atmospheric dryness, despite the tight connection with each other. Soil moisture changes exhibit more direct impacts of climate change on terrestrial processes and environments, e.g., resulting in different dryland changes. Changes in soil moisture persistence reflect changes in soil moisture regimes and the profound responses and feedbacks in terrestrial environments to climate change.

\section{c. Limitations and uncertainty}

Some caveats in the present study should be noted. First, this study is focused on intra-annual persistence on the daily scale,
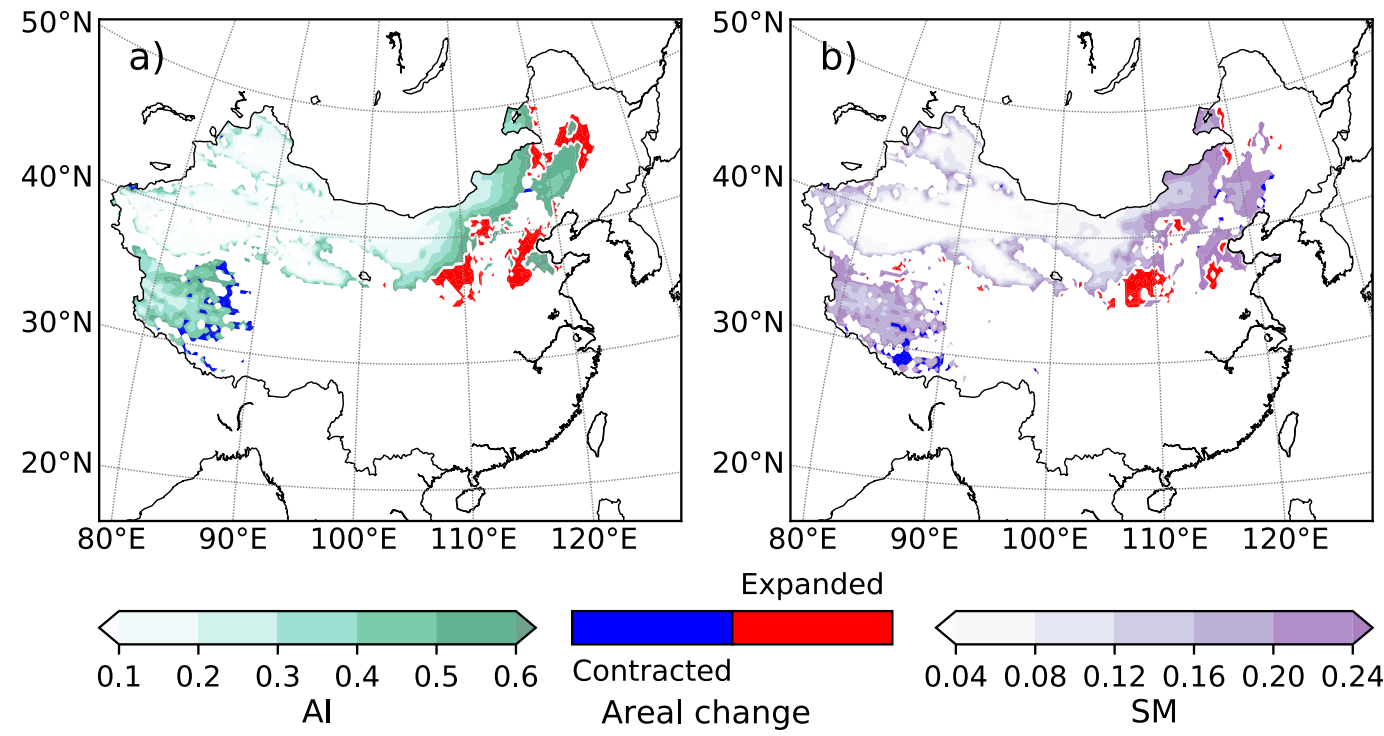

FIG. 13. As in Fig. 12, but for the comparison between the 1990s and 1980s. 
and in quantitative terms, the estimates are somewhat different from those of interannual persistence or those based on monthly mean soil moisture, owing to the filtering effects of various time intervals. Second, the analysis using soil moisture data is taken from the ERA5 reanalysis. Its model system has yet to explicitly represent land-use change and groundwater effects on soil moisture and thus may omit some information on soil moisture persistence. Third, comparisons of the ERA5 soil moisture to in situ observations show varying degrees of disagreements in long-term variabilities, and resolving this issue will require many more observations at various soil depths in order to perform more rigorous validation in the future. If the disagreement is attributed to the ERA5 soil moisture biases, more care should be taken in long-term trend analyses using this reanalysis soil moisture data. Moreover, the scale mismatch between observational sites and model grid cells should be taken into account in terms of the effectiveness of validation using in situ observations. Additionally, by now, there are still large areas in China that are not covered by observational networks (e.g., the western Tibetan Plateau). In these areas, the variability in soil moisture persistence might be the result of uncertainties and errors from the biases in the reanalysis soil moisture product. In the future, other components of terrestrial cycles, e.g., runoff and evapotranspiration, should be compared to cross-examine the soil moisture dataset once observations are available. Fourth, the lag autocorrelation analysis framework combines negative and positive soil moisture anomalies. Assessment of the separate persistence of the two types of soil moisture anomalies could be more helpful in understanding the regional impacts of climate change.

\section{Summary and conclusions}

In the present study, the variability in intra-annual persistence of soil moisture across China during 1979-2018 is examined using the ERA5 reanalysis from the ECMWF. The ERA5 soil moisture dataset is first validated against in situ observations, and ERA5 is verified to be able to reasonably represent soil moisture evolutions from daily to annual time scales.

Based on the framework of lag autocorrelation, the estimation reveals a considerable increase in soil moisture persistence with soil depth. In the upper and root layers, the maximum persistence (over 30 days) occurs in the transition zone and regions with large soil moisture variabilities. In the deep layer, the mean persistence grows to 115 days in the arid zone and 60 days in the humid zone, and the spatial gradient appears to be opposite that of soil moisture. Persistence is prolonged in autumn, and the seasonality intensifies with soil depth. On decadal scales, soil moisture persistence shows predominant increases across drylands, especially in the lower soil layer, contributing to the intensification of soil droughts and the expansion of dryland areas over the last four decades.

The changed soil moisture persistence indicates the variability in soil hydrological regimes under a changing climate and the potentially profound responses of terrestrial environments to climate change. These findings identify the implications of the impacts of climate change in terms of terrestrial hydrological cycle variability. In the future, the role of soil moisture in climate change impact evaluations should be studied further.
Acknowledgments. This study was jointly sponsored by the National Key R\&D Program of China (2018YFA0606002), the National Natural Science Foundation of China (41575087, 42075171), the Jiangsu Collaborative Innovation Center for Climate Change, and the U.K.-China Research and Innovation Partnership Fund through the Met Office Climate Science for Service Partnership (CSSP) China as part of the Newton Fund.

\section{REFERENCES}

Adler, R. F., G. J. Gu, M. Sapiano, J. J. Wang, and G. J. Huffman, 2017: Global precipitation: Means, variations and trends during the satellite era (1979-2014). Surv. Geophys., 38, 679-699, https://doi.org/10.1007/s10712-017-9416-4.

Albergel, C., P. de Rosnay, C. Gruhier, J. Muñoz-Sabater, S. Hasenauer, L. Isaksen, Y. Kerr, and W. Wagner, 2012: Evaluation of remotely sensed and modelled soil moisture products using global ground-based in situ observations. Remote Sens. Environ., 118, 215-226, https://doi.org/10.1016/j.rse.2011.11.017.

Balsamo, G., F. Pappenberger, E. Dutra, P. Viterbo, and B. van den Hurk, 2011: A revised land hydrology in the ECMWF model: A step towards daily water flux prediction in a fullyclosed water cycle. Hydrol. Processes, 25, 1046-1054, https:// doi.org/10.1002/hyp.7808.

— face reanalysis data set. Hydrol. Earth Syst. Sci., 19, 389-407, https://doi.org/10.5194/hess-19-389-2015.

Bell, K. R., B. J. Blanchard, T. J. Schmugge, and M. W. Witczak, 1980: Analysis of surface moisture variations within large-field sites. Water Resour. Res., 16, 796-810, https://doi.org/10.1029/ WR016i004p00796.

Box, G. E. P., and D. R. Cox, 1964: An analysis of transformations. J. Roy. Stat. Soc., 26B, 211-252, https://doi.org/10.1111/J.25176161.1964.TB00553.X.

Chang, L.-L., and Coauthors, 2018: Why do large-scale land surface models produce a low ratio of transpiration to evapotranspiration? J. Geophys. Res. Atmos., 123, 9109-9130, https:// doi.org/10.1029/2018JD029159.

Chen, N., C. Xiao, F. Pu, X. Wang, C. Wang, Z. Wang, and J. Gong, 2015: Cyber-physical geographical information service-enabled control of diverse in-situ sensors. Sensors, 15, 2565-2592, https:// doi.org/10.3390/s150202565.

Cleveland, R. B., W. S. Cleveland, J. E. McRae, and I. Terpenning, 1990: STL: A seasonal-trend decomposition. J. Off. Stat., 6, 3-73.

Cleveland, W. S., 1979: Robust locally weighted regression and smoothing scatterplots. J. Amer. Stat. Assoc., 74, 829-836, https://doi.org/10.1080/01621459.1979.10481038.

Coenders-Gerrits, A. M., R. J. van der Ent, T. A. Bogaard, L. Wang-Erlandsson, M. Hrachowitz, and H. H. Savenije, 2014: Uncertainties in transpiration estimates. Nature, 506, E1-E2, https://doi.org/10.1038/nature12925.

Cowan, I. R., 1965: Transport of water in the soil-plant-atmosphere system. J. Appl. Ecol., 2, 221-239, https://doi.org/10.2307/ 2401706.

D’Agostino, R. B., 1971: An omnibus test of normality for moderate and large size samples. Biometrika, 58, 341-348, https:// doi.org/10.1093/biomet/58.2.341.

Dai, Y., W. Shangguan, Q. Duan, B. Liu, S. Fu, and G. Niu, 2013: Development of a China dataset of soil hydraulic parameters using pedotransfer functions for land surface modeling. J. Hydrometeor., 14, 869-887, https://doi.org/10.1175/ JHM-D-12-0149.1. 
Dardel, C., L. Kergoat, P. Hiernaux, E. Mougin, M. Grippa, and C. J. Tucker, 2014: Re-greening Sahel: 30 years of remote sensing data and field observations (Mali, Niger). Remote Sens. Environ., 140, 350-364, https://doi.org/10.1016/j.rse.2013.09.011.

Delworth, T., and S. Manabe, 1988: The influence of potential evaporation on the variabilities of simulated soil wetness and climate. J. Climate, 1, 523-547, https://doi.org/10.1175/15200442(1988)001<0523:TIOPEO >2.0.CO;2.

— atmospheric variability. J. Climate, 2, 1447-1462, https:// doi.org/10.1175/1520-0442(1989)002<1447:TIOSWO>2.0. $\mathrm{CO} ; 2$.

Djebou, D. C. S., and V. P. Singh, 2015: Retrieving vegetation growth patterns from soil moisture, precipitation and temperature using maximum entropy. Ecol. Modell., 309-310, 1021, https://doi.org/10.1016/j.ecolmodel.2015.03.022.

Dorigo, W. A., and Coauthors, 2011: The international soil moisture network: A data hosting facility for global in situ soil moisture measurements. Hydrol. Earth Syst. Sci., 15, 16751698, https://doi.org/10.5194/hess-15-1675-2011.

Emanuel, R. E., P. D'Odorico, and H. E. Epstein, 2007: A dynamic soil water threshold for vegetation water stress derived from stomatal conductance models. Water Resour. Res., 43, W03431, https://doi.org/10.1029/2005WR004831.

Feng, S., and Q. Fu, 2013: Expansion of global drylands under a warming climate. Atmos. Chem. Phys., 13, $10081-10094$, https://doi.org/10.5194/acp-13-10081-2013.

Gao, C., H. Chen, S. Sun, V. Ongoma, W. Hua, H. Ma, B. Xu, and Y. Li, 2018: A potential predictor of multi-season droughts in southwest China: Soil moisture and its memory. Nat. Hazards, 91, 553-566, https://doi.org/10.1007/s11069-017-3140-8.

Green, J. K., S. I. Seneviratne, A. M. Berg, K. L. Findell, S. Hagemann, D. M. Lawrence, and P. Gentine, 2019: Large influence of soil moisture on long-term terrestrial carbon uptake. Nature, 565, 476-479, https://doi.org/10.1038/s41586-018-0848-x.

Gu, X. H., Q. Zhang, V. P. Singh, and P. J. Shi, 2017: Changes in magnitude and frequency of heavy precipitation across China and its potential links to summer temperature. J. Hydrol., 547, 718-731, https://doi.org/10.1016/j.jhydrol.2017.02.041.

Haines, W. B., 1930: Studies in the physical properties of soil. V. The hysteresis effect in capillary properties, and the modes of moisture distribution associated therewith. J. Agric. Sci., 20, 97-116, https://doi.org/10.1017/S002185960008864X.

Hersbach, H., and Coauthors, 2018: Operational global reanalysis: Progress, future directions and synergies with NWP. ERA Rep. Series 27, 65 pp., https://doi.org/10.21957/tkic6g3wm.

Hsiao, T. C., and E. Acevedo, 1974: Plant responses to water deficits, water-use efficiency, and drought resistance. Agric. Meteor., 14, 59-84, https://doi.org/10.1016/0002-1571(74)90011-9.

Huang, J., L. Gao, and X. Chen, 2015: Temporal-spatial characteristics of different rainfall levels in Fujian Province from 1960 to 2011 (in Chinese). Sci. Soil Water Conserv., 13, 17-23.

Huang, J. P., H. P. Yu, X. D. Guan, G. Y. Wang, and R. X. Guo, 2016: Accelerated dryland expansion under climate change. Nat. Climate Change, 6, 166-171, https://doi.org/10.1038/nclimate2837.

Jin, R., and Coauthors, 2014: A nested ecohydrological wireless sensor network for capturing the surface heterogeneity in the midstream areas of the Heihe River basin, China. IEEE Geosci. Remote Sens. Lett., 11, 2015-2019, https://doi.org/ 10.1109/LGRS.2014.2319085.

Koster, R. D., and M. J. Suarez, 2001: Soil moisture memory in climate models. J. Hydrometeor., 2, 558-570, https://doi.org/ 10.1175/1525-7541(2001)002<0558:SMMICM>2.0.CO;2.
— , and Coauthors, 2010: Contribution of land surface initialization to subseasonal forecast skill: First results from a multimodel experiment. Geophys. Res. Lett., 37, L02402, https:// doi.org/10.1029/2009GL041677.

Lei, Y. B., and K. Yang, 2017: The cause of rapid lake expansion in the Tibetan Plateau: Climate wetting or warming? WIREs Water, 4, e1236, https://doi.org/10.1002/wat2.1236.

Li, H. B., A. Robock, S. X. Liu, X. G. Mo, and P. Viterbo, 2005: Evaluation of reanalysis soil moisture simulations using updated Chinese soil moisture observations. J. Hydrometeor., 6 , 180-193, https://doi.org/10.1175/JHM416.1.

Li, J. S., and H. Kawano, 1996: The areal distribution of soil moisture under sprinkler irrigation. Agric. Water Manage., 32, 29-36, https://doi.org/10.1016/S0378-3774(96)01261-9.

Li, M., and Z. Ma, 2015: Soil moisture drought detection and multitemporal variability across China. Sci. China Earth Sci., 58, 1798-1813, https://doi.org/10.1007/s11430-015-5076-8.

_ $\mathrm{P}$. Wu, and Z. Ma, 2020: A comprehensive evaluation of soil moisture and soil temperature from third-generation atmospheric and land reanalysis data sets. Int. J. Climatol., https:// doi.org/10.1002/JOC.6549, in press.

_, Z. Ma, H. P. Gu, Q. Yang, and Z. Y. Zheng, 2017: Production of a combined land surface data set and its use to assess land-atmosphere coupling in China. J. Geophys. Res. Atmos., 122, 948-965, https://doi.org/10.1002/2016 JD025511.

Liu, S. X., X. G. Mo, H. B. Li, G. B. Peng, and A. Robock, 2001: Spatial variation of soil moisture in China: Geostatistical characterization. J. Meteor. Soc. Japan, 79, 555-574, https:// doi.org/10.2151/jmsj.79.555.

Liu, Y. Q., and R. Avissar, 1999: A study of persistence in the landatmosphere system using a general circulation model and observations. J. Climate, 12, 2139-2153, https://doi.org/10.1175/ 1520-0442(1999)012<2139:ASOPIT>2.0.CO;2.

Liu, Z. Y., 2010: Bimodality in a monostable climate-ecosystem: The role of climate variability and soil moisture memory. J. Climate, 23, 1447-1455, https://doi.org/10.1175/2009JCLI3183.1.

Mahanama, S. P. P., and R. D. Koster, 2005: AGCM biases in evaporation regime: Impacts on soil moisture memory and land-atmosphere feedback. J. Hydrometeor., 6, 656-669, https://doi.org/10.1175/JHM446.1.

MahfuzurRahman, M., and M. Lu, 2015: Characterizing soil moisture memory by soil moisture autocorrelation. J. Water Res. Hydraul. Eng., 3, 85-94.

Maidment, D. R., 1993: Handbook of Hydrology. 1st ed. McGrawHill Education, 1424 pp.

Matsumura, S., and K. Yamazaki, 2012: A longer climate memory carried by soil freeze-thaw processes in Siberia. Environ. Res. Lett., 7, 045402, https://doi.org/10.1088/1748-9326/7/4/045402.

McColl, K. A., Q. He, H. Lu, and D. Entekhabi, 2019: Short-term and long-term surface soil moisture memory time scales are spatially anticorrelated at global scales. J. Hydrometeor., 20, 1165-1182, https://doi.org/10.1175/JHM-D-18-0141.1.

Middleton, N. J., and D. S. Thomas, 1992: World Atlas of Desertification. 2nd ed. Arnold Publ. London, 182 pp.

Milly, P. C., K. A. Dunne, and A. V. Vecchia, 2005: Global pattern of trends in streamflow and water availability in a changing climate. Nature, 438, 347-350, https://doi.org/10.1038/nature04312.

Orth, R., and S. I. Seneviratne, 2012: Analysis of soil moisture memory from observations in Europe. J. Geophys. Res., 117, D15115, https://doi.org/10.1029/2011JD017366.

$\longrightarrow$, and —, 2013: Propagation of soil moisture memory to streamflow and evapotranspiration in Europe. Hydrol. Earth 
Syst. Sci., 17, 3895-3911, https://doi.org/10.5194/hess-17-38952013.

Piao, S. L., L. Yin, X. H. Wang, P. Ciais, S. S. Peng, Z. H. Shen, and S. I. Seneviratne, 2009: Summer soil moisture regulated by precipitation frequency in China. Environ. Res. Lett., 4, 044012, https://doi.org/10.1088/1748-9326/4/4/044012.

Ryu, D., and J. S. Famiglietti, 2005: Characterization of footprintscale surface soil moisture variability using Gaussian and beta distribution functions during the southern Great Plains 1997 (SGP97) hydrology experiment. Water Resour. Res., 41, W12433, https://doi.org/10.1029/2004WR003835.

Santanello, J. A., and Coauthors, 2018: Land-atmosphere interactions: The LoCo perspective. Bull. Amer. Meteor. Soc., 99, 1253-1272, https://doi.org/10.1175/BAMS-D-17-0001.1.

Schewe, J., and Coauthors, 2019: State-of-the-art global models underestimate impacts from climate extremes. Nat. Commun., 10, 1005, https://doi.org/10.1038/s41467-019-08745-6.

Schwalm, C. R., and Coauthors, 2017: Global patterns of drought recovery. Nature, 548, 202-205, https://doi.org/10.1038/nature23021.

Seneviratne, S. I., and Coauthors, 2006: Soil moisture memory in AGCM simulations: Analysis of Global Land-Atmosphere Coupling Experiment data. J. Hydrometeor., 7, 1090-1112, https://doi.org/10.1175/JHM533.1.

—, T. Corti, E. L. Davin, M. Hirschi, E. B. Jaeger, I. Lehner, B. Orlowsky, A. J. Teuling, 2010: Investigating soil moistureclimate interactions in a changing climate: A review. Earth-Sci. Rev., 99, 125-161, https://doi.org/10.1016/j.earscirev.2010.02.004.

Shinoda, M., 2001: Climate memory of snow mass as soil moisture over central Eurasia. J. Geophys. Res., 106, 33 393-33 403, https://doi.org/10.1029/2001JD000525.

Su, Z., J. Wen, L. Dente, R. van der Velde, L. Wang, Y. Ma, K. Yang, Z. Hu, 2011: The Tibetan Plateau observatory of plateau scale soil moisture and soil temperature (Tibet-Obs) for quantifying uncertainties in coarse resolution satellite and model products. Hydrol. Earth Syst. Sci., 15, 2303-2316, https://doi.org/10.5194/hess-15-2303-2011.

Vetter, M., and Coauthors, 2008: Analyzing the causes and spatial pattern of the European 2003 carbon flux anomaly using seven models. Biogeosciences, 5, 561-583, https://doi.org/10.5194/bg-5-561-2008.

Viterbo, P., and A. C. M. Beljaars, 1995: An improved land-surface parameterization scheme in the ECMWF model and its validation. J. Climate, 8, 2716-2748, https://doi.org/10.1175/15200442(1995)008<2716:AILSPS>2.0.CO;2.

,-- J. F. Mahfouf, and J. Teixeira, 1999: The representation of soil moisture freezing and its impact on the stable boundary layer. Quart. J. Roy. Meteor. Soc., 125, 2401-2426, https:// doi.org/10.1002/qj.49712555904.

Wang, A. H., and X. L. Shi, 2019: A multilayer soil moisture dataset based on the gravimetric method in China and its characteristics. J. Hydrometeor., 20, 1721-1736, https://doi.org/10.1175/ JHM-D-19-0035.1.

Wu, W. R., M. A. Geller, and R. E. Dickinson, 2002: A case study for land model evaluation: Simulation of soil moisture amplitude damping and phase shift. J. Geophys. Res., 107, 4793, https://doi.org/10.1029/2001JD001405.

Yan, Z. Q., Y. P. Zhang, Z. H. Zhou, and N. Han, 2017: The spatiotemporal variability of droughts using the standardized precipitation index in Yunnan, China. Nat. Hazards, 88, 1023-1042, https://doi.org/10.1007/s11069-017-2904-5.

Yang, J., H. Tian, S. Pan, G. Chen, B. Zhang, and S. Dangal, 2018: Amazon drought and forest response: Largely reduced forest photosynthesis but slightly increased canopy greenness during the extreme drought of 2015/2016. Global Change Biol., 24, 1919-1934, https://doi.org/10.1111/gcb.14056.

Yang, K., and C. H. Wang, 2019: Seasonal persistence of soil moisture anomalies related to freeze-thaw over the Tibetan Plateau and prediction signal of summer precipitation in eastern China. Climate Dyn., 53, 2411-2424, https://doi.org/ 10.1007/s00382-019-04867-1.

- , and Coauthors, 2013: A multiscale soil moisture and freezethaw monitoring network on the third pole. Bull. Amer. Meteor. Soc., 94, 1907-1916, https://doi.org/10.1175/BAMS-D12-00203.1.

—, H. Wu, J. Qin, C. Lin, W. Tang, and Y. Chen, 2014: Recent climate changes over the Tibetan Plateau and their impacts on energy and water cycle: A review. Global Planet. Change, 112, 79-91, https://doi.org/10.1016/j.gloplacha.2013.12.001.

Yeh, T. C., R. T. Wetherald, and S. Manabe, 1984: The effect of soil moisture on the short-term climate and hydrology change-A numerical experiment. Mon. Wea. Rev., 112, 474-490, https:// doi.org/10.1175/1520-0493(1984)112<0474:TEOSMO>2.0. $\mathrm{CO} ; 2$.

Zhang, G. Q., W. Luo, W. F. Chen, and G. X. Zheng, 2019: A robust but variable lake expansion on the Tibetan Plateau. Sci. Bull., 64, 1306-1309, https://doi.org/10.1016/ j.scib.2019.07.018.

Zhang, Y., X. Xiao, X. Wu, S. Zhou, G. Zhang, Y. Qin, and J. Dong, 2017: A global moderate resolution dataset of gross primary production of vegetation for 2000-2016. Sci. Data, 4, 170165, https://doi.org/10.1038/sdata.2017.165. 